\title{
ARTICLE
}

\section{Experimental Design to Enhance Dopamine Electrochemical Detection Using Carbon Paste Electrodes}

Soraya Adriane Blum ${ }^{1}$ iD, Felipe Zahrebelnei ${ }^{1}$ iD, Noemi Nagata ${ }^{2}$ iD, Valtencir Zucolotto $^{3}$ iD, Luiz Henrique Capparelli Mattoso ${ }^{4}$ iD, Christiana Andrade Pessoa ${ }^{1}$ iD, Jarem Raul Garcia ${ }^{1}$ (D), Karen Wohnrath ${ }^{1 *}$ iD

${ }^{1}$ Departamento de Química, Universidade Estadual de Ponta Grossa, Av. Carlos Cavalcanti, 4748, ZC 84030-900, Ponta Grossa, PR, Brazil

${ }^{2}$ Departamento de Química, Universidade Federal do Paraná, Centro Politécnico, ZC 81531-980, Curitiba, PR, Brazil

${ }^{3}$ Instituto de Física de São Carlos, Universidade de São Paulo, Av. Trabalhador São-carlense, 400, Parque Arnold Schimidt, ZC 13566-590, São Carlos, SP, Brazil

${ }^{4}$ Laboratório Nacional de Nanotecnologia Aplicada ao Agronegócio (LNNA), Embrapa Instrumentação, ZC 13560-970, São Carlos, SP, Brazil

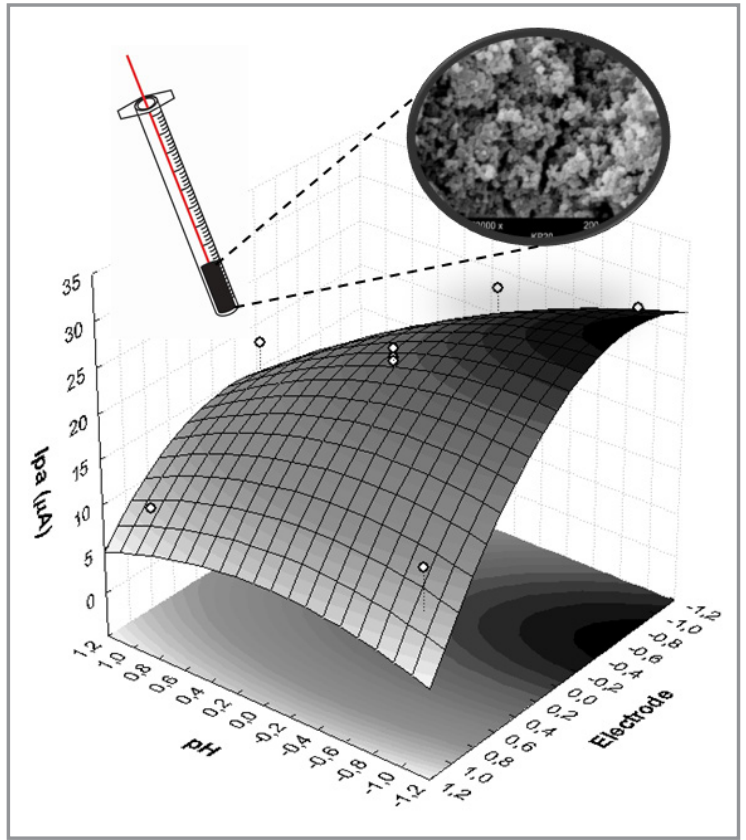

Efforts have been made on the development of new modified electrodes to be used in the fast determination of neurotransmitters, either in commercial drugs or in biological samples. Determination of dopamine (DA), for example, is of great importance since the lack of this neurotransmitter is related to many neurological disorders, including Parkinson's and Alzheimer's diseases. In this paper, we present a detailed electrochemical characterization, as well as DA detection studies of paste electrodes incorporating carbon materials in different allotropic forms, including carbon black modified with intrinsically conducting polymers (Eeonomers $^{\circledR}$ ), pristine carbon black, graphite, and carbon nanotubes. Emphasis is put on the smaller particle size and larger specific surface area of CB Eeonomers ${ }^{\circledR}$ materials, which led to an improved electroanalytical performance for the developed devices. The electrodes fabricated with Eeonomers ${ }^{\circledR}$ modified with polyaniline exhibited the highest current response towards DA detection, in addition to the ability of distinguishing DA from its natural interferent, ascorbic acid. Furthermore, a central composite design was used to investigate the influence of $\mathrm{pH}$ and electrode composition (proportion of Eeonomers ${ }^{\circledR}$ ) on the electrochemical sensing of DA. A greater

Cite: Blum, S. A.; Zahrebelnei, F.; Nagata, N.; Zucolotto, V.; Mattoso, L. H. C.; Pessoa, C. A.; Garcia, J. R.; Wohnrath, K. Experimental Design to Enhance Dopamine Electrochemical Detection Using Carbon Paste Electrodes. Braz. J. Anal. Chem., 2021, 8 (32), pp 178-197. doi: http://dx.doi.org/10.30744/brjac.2179-3425.AR-31-2021 
sensitivity was achieved for 50:50 (w/w) KP20/KPy20 electrode at pH 7.0. The optimized devices showed to be promising tools to perform quick, cheap and sensitive detection of this neurotransmitter in bioanalytical systems.

Keywords: carbon paste electrode, carbon black, intrinsically conducting polymers, electroanalysis, electrocatalysis, response surface, factorial design.

\section{INTRODUCTION}

Research on the development of new carbon paste electrodes (CPEs) have experienced a fast growth since the first reports by Adams [1]. CPEs have been widely used in electroanalysis due to their low background current, wide work potential window, chemical stability and low cost. CPEs can also be chemically modified, which can significantly improve their sensibility, selectivity and overall analytical performance towards the detection of a number of analytes [2-4].

The use of carbonaceous materials for constructing CPEs has been enabling the production of excellent detection devices with diversified applications [5]. Several carbon allotropes and nanomaterials have been investigated in this regard, including glassy carbon (GC) [6], graphite (GP) [7], carbon nanotubes (CNT) [8-9], carbon nanofibers [10] and graphene [11-12].

Carbon nanotubes (CNT) have also attracted attention as promising materials for modified electrodes, allowing the fabrication of highly sensitive and selective devices. Indeed, the electrochemical applications of CNTs have been greatly explored, particularly on battery technology [13], supercapacitors [14], and sensors and actuators [15-18]. CNTs are excellent electrode materials because of their unique electronic and mechanical properties, as well as their low chemical reactivity exhibited in most electrolyte solutions, retaining a high surface activity and a wide operational potential window [19]. Single-walled carbon nanotubes (SWCNTs) and multi-walled carbon nanotubes (MWCNTs) made into paste electrodes, using mineral oil as agglutinant, are also valuable tools for detection of several molecules [20-22]. Valentini et al [23] described for the first time the electrochemical behavior and the electroanalytical performance of a SWCNT paste electrode, which exhibited a sensitivity enhancement toward dopamine oxidation, in comparison to graphite-based CPEs.

Another important carbon material is carbon black (CB), which is a paracrystalline form of carbon, presenting small particle size and large specific surface area. CB particles grown together to form aggregates of different sizes and shapes. This material has been employed as an alternative carbon allotropic form for applications as electroconductive additive in hydrogen storage devices, and as cathode materials in lithium-ion micro-batteries [18]. The use of CB as active materials in CPEs has also been intensively investigated due to their excellent electrical conductivity and presence of several defect sites. Those properties contribute to faster electron transfer kinetics on the electrodic material, providing interesting abilities to mediate electron transfer reactions for some analytes [25-27]. Additionally, CB-based paste electrodes have been produced in a variety of configurations by exploiting the versatility of carbon paste and CB nanomaterial.

DA is a biological amine that has excitatory and inhibitory activity in postsynaptic membranes, performing essential roles in the endocrine, cardiovascular, excretory and central nervous systems [28]. In physiological samples, DA concentration ranges from $10^{-6}$ to $10^{-9} \mathrm{~mol} \mathrm{~L}^{-1}$ [29], and changes in these levels are related to several neurological disorders, such as Parkinson's disease, Alzheimer's disease and schizophrenia, among others. This neurotransmitter is also used as an intravenous resuscitation medication in hospitals, which demands a rigorous quality control to ensure the effectiveness and safety of this drug [30]. In these contexts, the development of fast and low-cost methods for detecting DA in biological fluids and pharmaceutical formulations is fundamental for the clinical field and pharmaceutical industry.

The method commonly used for DA analysis is high-performance liquid chromatography (HPLC). This method exhibits high sensitivity and excellent selectivity; however, it has important drawbacks, such as the need for expensive equipment, demand for trained technicians, complex sample preparation 
procedures and the impossibility of in situ analysis. In contrast, electrochemical methods can overcome these disadvantages, in addition to present high sensitivity, good selectivity, quick response, and lower cost. Furthermore, the instrumentation required for electroanalytical determinations is simple and can be conveniently miniaturized, which enables its use for in situ and automated detections [31-33]. Due to the mentioned advantages, the development of new low-cost, selective, sensitive and simple devices for DA detection is justified.

When working with the advatangeous electrochemical sensors, it is also extremely important that these devices allow analyzes to be carried out on complex samples, such as biological samples. DA is easily detected due to its easy oxidation, however, in physiological samples, several substances coexist that can interfere with its electrochemical detection [34]. There is a large amount of work describing methodologies for the detection of DA with high sensitivity, but its selective detection remains a major challenge for researchers. The literature presents us two important interfering substances in DA electrochemical detection process: uric acid (UA) and ascorbic acid (AA), with AA as the most important because it is found naturally as a vital antioxidant against biological oxidation process [35]. These two compounds stand out due to their oxidation potential being close to the DA one and to the fact that their concentrations being hundreds of thousands of times higher than the concentration of DA in physiological environment. Additionally, the oxidation products of these compounds can be potentially absorbed or electropolymerized on the surface of the electrodes, reducing sensors reuse and reproducibility. Therefore, for a DA sensor to be actually used in real samples, selectivity is crucial [35].

The use of multivariate optimization tools, such as factorial design and response surface methodology (RSM), has showed to be advantageous for optimizing experimental parameters and conditions in a number of systems in both research laboratories and industry. In the electroanalytical field, the usage of such approaches has been leading to enhanced detection performances for several sensing devices. For instance, recent literature shows various studies in which the use of factorial designs has enabled significant improvements in important analytical parameters, such as selectivity [36-37] and sensitivity [3839], for different electrochemical sensing systems.

In this study, we describe the preparation of CPEs for the electrochemical detection of DA, with emphasis on the use of CB modified with conducting polymers, namely polyaniline (Pani) and polypyrrole (PPy). Conducting polymer-modified carbon black (Eeonomers ${ }^{\circledR}$ ) [29] is a thermally stable conductive material made via in situ deposition of intrinsically conducting polymers. These materials have found applications mainly as electroactive fillers in polymeric composites with improved processing properties [30-32]. However, the presence of Pani and PPy on the CB surface provides a significant increase in the electrical conductivity of the material and in the number of surface active sites due to the presence of alternating double and single bonds [46] and nitrogen atoms on the polymeric structure $[47,48]$. The incorporation of such polymers onto CB particles can enhance their conductive properties and electroactivity, which significantly impacts their sensing capability. These characteristics were explored in this work to develop sensitive, selective and feasible electrochemical sensors to perform DA determination in real samples.

\section{MATERIALS AND METHODS \\ Chemicals}

All chemicals were of analytical grade and used as received. Dopamine hydrochloride and multiwalled carbon nanotubes were purchased from Sigma-Aldrich. Ascorbic acid was purchased from Merck. Graphite powder was acquired from Fluka. Three different types of Eeonomers ${ }^{\circledR}$ (Eeonyx Co) were used, including pure CB (KP0 - specific surface area of ca. $1400 \mathrm{~m}^{2} / \mathrm{g}$ ), CB modified with 20 wt\% polyaniline, KP20 (particle size $40 \mathrm{~nm}$, specific surface area of ca. $570 \mathrm{~m}^{2} / \mathrm{g}$ and density of $0.062 \mathrm{~g} / \mathrm{cm}^{3}$ ) and CB modified with $20 \mathrm{wt} \%$ of polypirrole, KPy20 (particle size $40 \mathrm{~nm}$, specific surface area of ca. $390 \mathrm{~m}^{2} / \mathrm{g}$ and density of $0.062 \mathrm{~g} / \mathrm{cm}^{3}$ ). Details on synthesis, characterization and applications of Eeonomers ${ }^{\circledR} \operatorname{can}^{2}$ be found elsewhere [40-43]. Double distilled water was used to prepare all solutions. 


\section{Preparation of the carbon paste electrodes}

The unmodified graphite CPE (GRPE) was prepared by mixing graphite powder and mineral oil $(12 \%$ w/w). The unmodified MWCNT CPE (CNTPE) was prepared by mixing nanotube powder with $45 \%$ (w/w) of mineral oil. The unmodified pristine CB CPE (KPOPE) was prepared by mixing carbon black (KP0) powder with $14 \%(w / w)$ of mineral oil. The electrodes containing KP20 (KPPE) and KPy20 (KPyPE) were prepared by mixing the powders with $28 \% \mathrm{w} / \mathrm{w}$ and $26 \% \mathrm{w} / \mathrm{w}$ mineral oil, respectively.

$0.1 \mathrm{~g}$ of each paste was inserted into a plastic needle-type capillary tube measuring $6 \mathrm{~mm}$ diameter and $5 \mathrm{~cm}$ length, and a $1 \mathrm{~mm}$ diameter $\mathrm{Ni}-\mathrm{Cr}$ wire connected to a $5 \mathrm{~mm}$ diameter graphite cylinder was used as electrical contact. Electrode surfaces were smoothed using ordinary vegetal paper and rinsed carefully with double distilled water.

\section{Electrochemical measurements}

Electrochemical measurements were conducted with a conventional three-electrode cell using in a PalmSens potentiostat (Palm Instruments BV). An $\mathrm{Ag} / \mathrm{AgCl}$ electrode (saturated with $\mathrm{KCl}$ ) and a platinum wire (fixed area at $0.8 \mathrm{~mm}^{2}$ ) served as the reference and auxiliary electrodes, respectively. The unmodified GRPE, CNTPE and KPOPE and the modified KPPE and KPyPE were used as working electrodes.

The electrochemical characterization of each CPE as well as DA and AA quantification were performed by using cyclic voltammetry, since this technique is the most suitable for a profound characterization in relation to the kinetic aspects of electrochemical reactions occurring in the electrode/solution interface. Cyclic voltammograms were recorded in the potential range from 0.0 to $0.8 \mathrm{~V} v s \mathrm{Ag} / \mathrm{AgCl}$, at scan rates of $10 \mathrm{mV} \mathrm{s}^{-1}$ and $90 \mathrm{mV} \mathrm{s}^{-1}$. $\mathrm{NaCl} 0.5 \mathrm{~mol} \mathrm{~L}^{-1}$ at $\mathrm{pH} 4.0$ (adjusted with $\mathrm{HCl} 0.1 \mathrm{~mol} \mathrm{~L}^{-1}$ ) was used as supporting electrolyte. Calibration curves were obtained for DA and AA in the range between 2 and $50 \mu \mathrm{mol} \mathrm{L}^{-1}$. All experiments were performed at room temperature.

\section{Experimental Design and Response Surface Methodology}

A systematic study was carried out to define the optimal conditions to obtain a higher anodic peak current (Ipa) in DA determination upon varying the proportion of the two different Eonomers ${ }^{\circledR}$ and $\mathrm{pH}$ of the supporting electrolyte. Using these parameters, optimization based on a $3^{2}$ factorial design and response surface methodology was performed. A set of 11 experiments was carried out.

The conducting polymer-modified Eeonomers ${ }^{\circledR}$ used were KP20 and KPy20. A mixture of these Eeonomers $^{\circledR}$ (KP20/KPy20) at 50:50 (w:w) was also used. Each electrode was prepared by mixing Eeonomers ${ }^{\circledR}$ with mineral oil $(28,26$ and $27 \%$, respectively). The $\mathrm{pH}$ supporting electrolyte was controlled using acetate buffer solution $(\mathrm{pH} 3.0,5.0$ and 7.0). The choice of $\mathrm{pH}$ and the proportion between the two conducting polymer-modified Eeonomers ${ }^{\circledR}$ as parameters on this experimental design is justified due to: (i) $\mathrm{pH}$ of the electrolyte solution plays an important role on the electrode response, since it can directly influence the conductivity of the system by polymer doping; (ii) the conducting polymer significantly influences the electrochemical response; hence, it is believed that the effect of the proportions of the different materials can reveal the individual role of each conducting polymer towards DA detection.

The stabilization of electrodes was performed with 25 cycles in the presence of supporting electrolyte. Subsequently, randomized electrochemical analyses in presence of $50 \mu \mathrm{mol} \mathrm{L-1} \mathrm{DA}$ were carried out in the potential range from 0 to $800 \mathrm{mV}$ vs Ag/AgCl, at $30 \mathrm{mV} \mathrm{s}^{-1}$, according to the conditions shown in Table V. The Ipa data were processed with Statistica software (version 5.0).

\section{DA Determination in Commercial Drugs}

Standard addition methodology was applied in the analysis of commercial DA injections containing 200 $\mathrm{mg}$ of Dopamine Hydrochloride. Aliquots of the commercial sample $(20 \mu \mathrm{L})$ were fortified with five additions of DA standard stock solution $\left(1 \times 10^{-2} \mathrm{~mol} \mathrm{~L}^{-1}\right)$. Finally, the solutions were analyzed by cyclic voltammetry using a previously prepared electrode containing the Eeonomer ${ }^{\circledR}$ KP20 (KPPE) and $\mathrm{NaCl}$ as supporting electrolyte. 


\section{RESULTS AND DISCUSSION \\ CPE preparation with different carbon materials}

As usual for CPE preparation, a paste consisting of carbonaceous powder and mineral oil as binder composes all electrodes. The amount of binder depends on the granulation of the carbon-based material and this proportion can cause increment of background current. According to Malha et al., 2013, as CB possesses high surface area, carbon pastes prepared with this material do require high amounts of binder $(25 \% \mathrm{w} / \mathrm{w})$ [44]. Ideal amount of binding agent was verified using cyclic voltammetry, and it was considered optimal when the resistive contribution on the voltammetric profile was not observed with the reduction on the amount of mineral oil (data not shown).

As Eeonomers ${ }^{\circledR}$ present larger specific surface area (see morphological analysis in Figure S1), a proper amount of CB was mixed with a suitable amount of mineral oil. As shown in the experimental section, KPO has the largest surface area and a lower percolation limit, thus it is expected a larger liquid surface accessible to the matrix and KPOPE was prepared by hand-mixing KP0 powder with $14 \%$ w/w mineral oil. This amount of binding agent is smaller than the one used for KP20 and KPy20,38\% w/w and $41 \%$ w/w, respectively. Higher amount of mineral oil was needed to disperse the modified Eeonomers ${ }^{\circledR}$ due to the presence of conducting polymers that present polar structure causing a decrease in the wettability of modified Eeonomers ${ }^{\circledR}$ related to the binder. Trying to avoid the use of higher amounts of mineral oil, KP20 and KPy20 materials were ground, and CPEs were prepared again and this new condition have resulted in a decreased mineral oil amount of $26 \% \mathrm{w} / \mathrm{w}$ and $28 \% \mathrm{w} / \mathrm{w}$ for KP20 and KPy20, respectively, which were employed as optimal electrode compositions.

GR and CNT-based paste electrodes were fabricated using the following proportions of mineral oil: $12 \%$ $\mathrm{w} / \mathrm{w}$ and $45 \% \mathrm{w} / \mathrm{w}$, respectively.

\section{Electrochemical behavior of different carbon materials}

The electrochemical behavior of all studied CPE was first investigated using the supporting electrolyte solution, $\mathrm{NaCl} 0.5 \mathrm{~mol} \mathrm{~L}^{-1}(\mathrm{pH}=4.0)$ at $30 \mathrm{mV} \mathrm{s}^{-1}$. Results are shown in Figure 1.

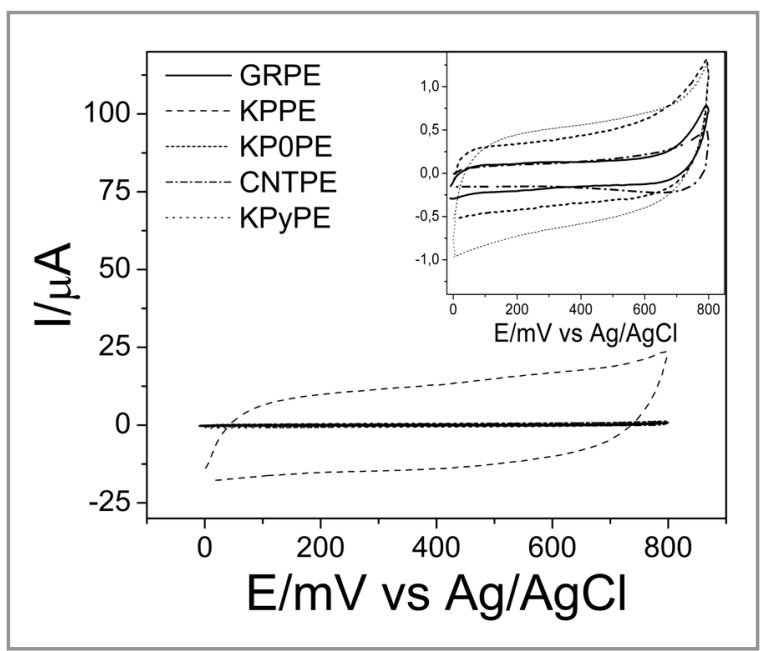

Figure 1. Cyclic voltammograms for the KPPE, KPyPE, KPOPE, GRPE and CNTPE, at $v=30 \mathrm{mV} \mathrm{s}^{-1}$. Supporting electrolyte: $\mathrm{NaCl} 0.5 \mathrm{~mol} \mathrm{~L}^{-1}$ at $\mathrm{pH}$ 4.0. For better visualization, the voltammograms for the KPyPE, KPOPE, GRPE and CNTPE electrodes are highlighted in an inset in the Figure.

The cyclic voltammograms for all paste electrodes exhibited different capacitive currents, according to the material employed for electrode fabrication. It is interesting to observe that neither the KPPE nor the KPyPE presented the characteristic voltammetric profile of the respective conducting polymer, since all of them did not present current peaks and only capacitive current was observed. This was assigned to the presence of polymeric films around the carbon black particles. In acidic solution, with the doping of the polymers, there is an increase on the conductivity of the materials. However, since the films are not thick enough to enable ion diffusion, only fast faradaic processes on the material surface occurs, creating a process known as pseudocapacitance [45]. 
It is interesting to notice that the capacitive current for the KPPE is 23 times higher than for its counterpart KPyPE, even considering that the specific area of the first one in only 1.5 times higher when compared to the former material. This can be understood considering that under acid doping PANI conductivity is higher than PPy [46]. In addition, the voltammograms obtained with the other CPE shows only capacitive current, probably due to Double Layer charging. It is also worth mentioning that the capacitive current for the unmodified CB is 30 times lower than the current observed for the KPPE, even though its specific area is 2.5 higher than the area for the KP20, fact that corroborate the occurrence of pseudocapacitive process in the modified Eeonomers ${ }^{\circledR}$.

Eeonomers ${ }^{\circledR}$ materials are produced with different proportions of conducting polymers. However, our studies have indicated that the material with $20 \%$ of polymers have demonstrated the most promising electrochemical behavior aiming the construction of electrochemical sensors (S2).

\section{Investigation of DA voltammetric behavior using different CPEs Electrodes}

The response of the different CPEs in presence of DA were investigated toward the oxidation process of the analyte. A well-defined anodic current peak was observed for all electrodes, which is attributed to the oxidation of dopamine to dopaminequinone, with the involvement of 2 electrons and 2 protons. This redox process has been extensively studied in the literature [47-50]. Figure 2.a displays the voltammmetric responses of the modified and unmodified Eeonomers ${ }^{\circledR}$ KPOPE, KPPE and KPyPE in the presence of DA. As discussed above, the most noticeable characteristic of the modified Eeonomers ${ }^{\circledR}$ is related to the presence of intense capacitive current, however both KPPE and KPyPE presented peak currents with absolute values (capacitive + faradaic current) higher than the ones exhibited by the unmodified Eeonomers $^{\circledR}$ KPOPE. Figure 2.b shows the voltammetric behavior for the electrodes prepared with different carbon allotropes used as reference. As expected, CNTPE (carbon nanotubes) presented a quasi-reversible voltammetric profile related to DA redox process. It is possible to observe a peak potential separation $(\Delta \mathrm{Ep})$ ca. $83 \mathrm{mV}$ and an anodic and cathodic peak current ratio for the process (Ipa/lpc) of ca. 1.2. The other two CPE showed on Figure 2.b also presented pronounced anodic peaks compared to the modified Eeonomers ${ }^{\circledR}$ (Figure 2.a). The parameters obtained from the measured cyclic voltammetry for the different carbon-based electrodes in presence of DA are showed in Table I.
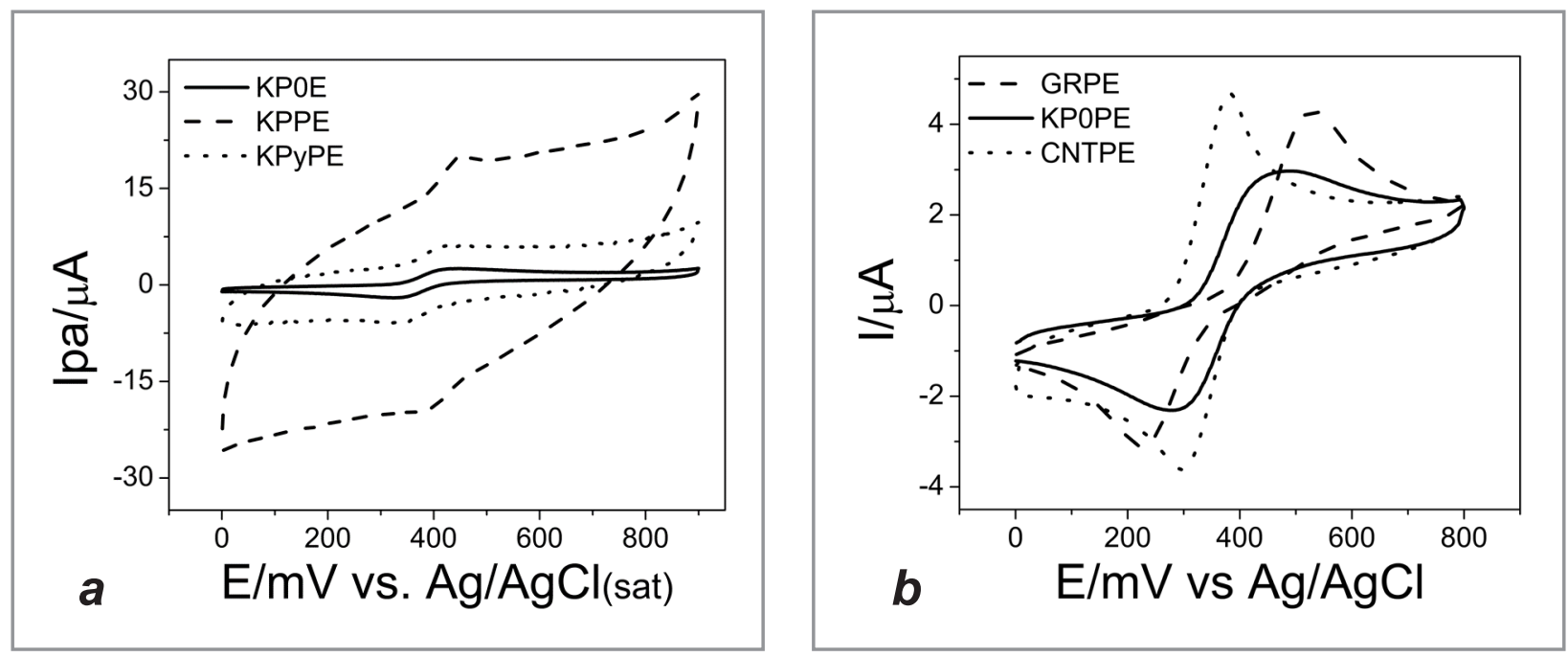

Figure 2. a) Cyclic voltammograms for the electrodes KPOPE, KPPE and KPyPE, and b) Cyclic voltammograms for the electrodes GRPE, KPOPE e CNTPE, in $50 \mu \mathrm{mol} \mathrm{L}^{-1}$ of DA. Supporting electrolyte: $\mathrm{NaCl} 0.5 \mathrm{~mol} \mathrm{~L}^{-1}, \mathrm{pH} 4.0$ and $v=30 \mathrm{mV} \mathrm{s}^{-1}$. 
Table I. Electrochemical parameters obtained from the cyclic voltammograms of GRPE, KPOPE, CNTPE, KPyPE and KPPE electrodes in the presence of $50 \mu \mathrm{mol} \mathrm{L-1}$ DA

\begin{tabular}{lcccccc}
\hline CPE & $E p_{\mathrm{a}}(\mathbf{m V})$ & $E p_{\mathrm{c}}(\mathbf{m V})$ & $\Delta E_{\mathrm{p}}=E p_{\mathrm{a}}-E p_{\mathrm{c}}(\mathbf{m V})$ & $I p_{\mathrm{a}}(\mu \mathrm{A})$ & $I p_{\mathrm{c}}(\mu \mathrm{A})$ & $I p_{\mathrm{a}} / I p_{\mathrm{c}}$ \\
\hline GRPE & 530.0 & 226.0 & 304.0 & 3.88 & -3.50 & -1.11 \\
CNTPE & 380.0 & 297.0 & 83.0 & 4.25 & -3.60 & -1.20 \\
KPOPE & 484.0 & 280.0 & 199.0 & 2.69 & -2.70 & -0.99 \\
KPyPE & 433.0 & 329.0 & 102.0 & 2.82 & -2.70 & -1.04 \\
KPPE & 454.0 & 387.0 & 67.0 & 5.98 & -6.01 & -0.99 \\
\hline
\end{tabular}

From Table I it is evidenced that, in addition to the CNTPE the two other electrodes that presented fast kinect for electron transfer for DA redox process are KPPE and KPyPE, even considering the presence of a high capacitive current. This behavior can be attributed to the smaller values of $\Delta \mathrm{E}_{\mathrm{p}}, 67$ and $102 \mathrm{mV}$, respectively (criteria for reversible process: $\Delta \mathbf{E}_{p}=57 / \boldsymbol{n} \mathrm{mV}$ at $25^{\circ} \mathrm{C}$ - where $\boldsymbol{n}$ is the number of electrons involved in the process and Ipa/lpc $=1.0$ ) [51]. The faster kinetics for DA redox process on KP20 and KPy20 can be assigned to the presence of the pseudocapacitance phenomena that is caused by fast faradaic processes occurring on the material surface as a consequence of the presence of polymeric conducting film at the modified Eeonomers ${ }^{\circledR}$. The Epa and Epc values shown in Table I were compared with those obtained with a conventional Pt electrode (Figure S3), in the same experimental conditions. We observed that oxidation of DA on a Pt electrode occurred at higher potentials (Epa= $504 \mathrm{mV}$ ). Another disadvantage on the use of Pt electrode is that DA adsorbs on the surface of this metal, which may lead to a fouling effect.

The effect of scan rate on the oxidation response of DA was examined in the range of $10-100 \mathrm{mV} \mathrm{s}^{-1}$ (Figure S4). The oxidation currents linearly increased with the square root of scan rate for all electrodes, indicating that the processes were diffusion-controlled, which is expected for catalytic systems and advantageous for quantitative determinations.

The ability of the electrodes to detect DA was investigated using $\mathrm{CV}$, in the range of 2 to $50 \mu \mathrm{mol} \mathrm{L}^{-1}$. For all electrodes employed, a linear relationship between the oxidation current and DA concentration was observed, allowing the determination of analytical parameters displayed in Table II.

Table II. Analytical parameters of DA determination using different carbon paste electrodes

\begin{tabular}{|c|c|c|c|c|}
\hline CPE & $\begin{array}{c}\text { Linear Regression } \\
\text { Equation }\end{array}$ & $\begin{array}{l}\text { Linear correlation } \\
\text { factor }\end{array}$ & $\begin{array}{l}\text { Sensitivity } \\
\text { (A mol-1 L) }\end{array}$ & $\begin{array}{c}\text { Linear Range of } \\
\text { Concentration } \\
\left(\mathrm{mol} \mathrm{L} \mathrm{L}^{-1}\right)\end{array}$ \\
\hline GRPE & $\mathrm{Ipa}=0.06+0.051[\mathrm{DA}]$ & 0.9930 & 0.051 & $2-50$ \\
\hline CNTPE & $\mathrm{Ipa}=0.02+0.065[\mathrm{DA}]$ & 0.9936 & $0.065 \pm 0.04$ & $2-50$ \\
\hline KPOPE & $\mathrm{Ipa}=0.02+0.043[\mathrm{DA}]$ & 0.9997 & 0.043 & $2-50$ \\
\hline KPyPE & $\mathrm{Ipa}=0.02+0.021[\mathrm{DA}]$ & 0.9983 & 0.021 & $2-50$ \\
\hline KPPE & $\mathrm{Ipa}=0.15+0.110[\mathrm{DA}]$ & 0.9958 & $0.110 \pm 0.04$ & $2-50$ \\
\hline
\end{tabular}


It is worth noticing that a wide linear range was obtained. A good sensitivity was observed for electrodes containing Eeonomer ${ }^{\circledR}$ KP20 (KPPE), followed by the CNT-containing electrodes (CNTPE).

Figure 3 shows the analytical curves obtained for the KPPE and CNTPE. The quantification of DA for these two electrodes were obtained in triplicate and the standard deviation is indicated for each point. It is also important to mention that the higher sensibility of KPPE electrode is clearly indicated in Figure 3 . It is also interesting to notice that the error on the measurement of the peak current for each of the studied DA concentrations is slightly smaller for the CNTPE electrode, probably due to the lower definition of the peaks on the KPPE.
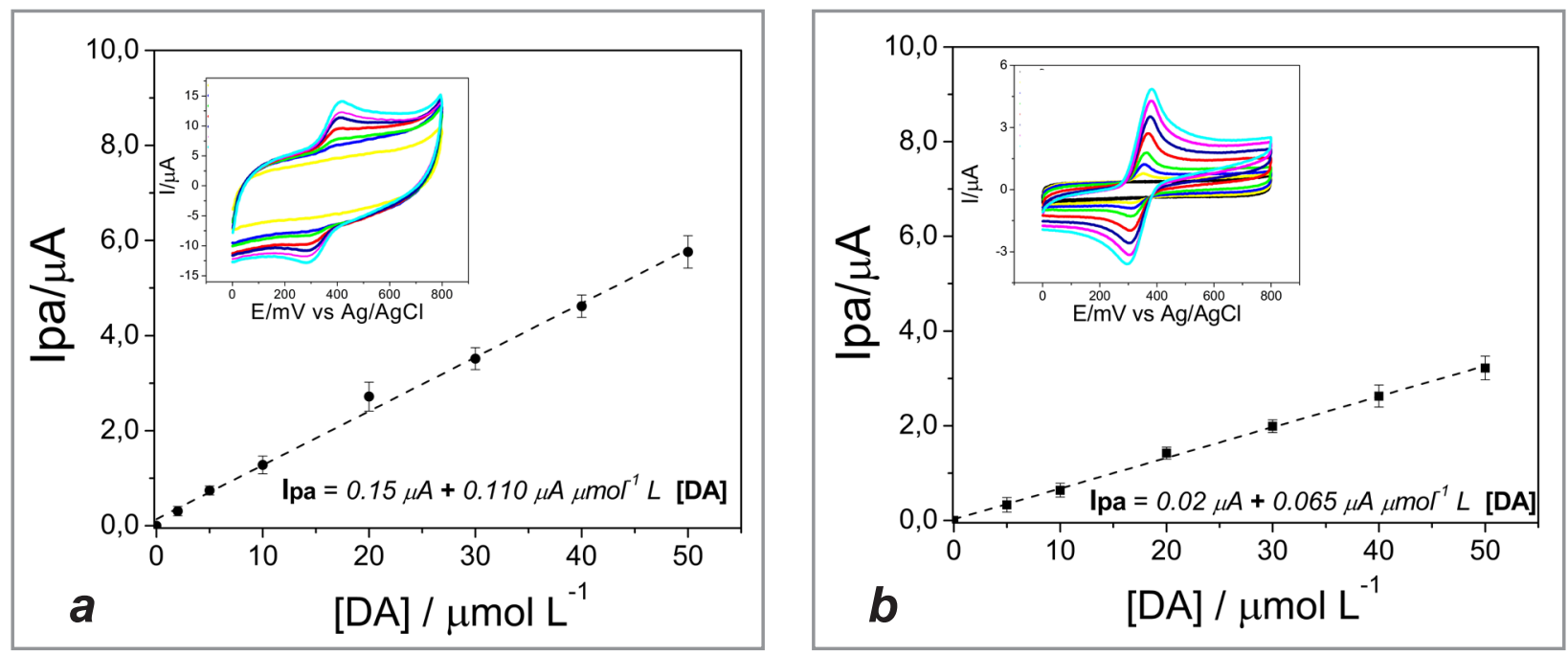

Figure 3. Analytical curves obtained by cyclic voltammetry in presence of DA for a) KPPE electrode and b) CNTPE electrode, both in the concentration range of 2 to $50 \mu \mathrm{mol} \mathrm{L}^{-1}$ of DA. Supporting electrolyte: $\mathrm{NaCl} 0.5 \mathrm{~mol} \mathrm{~L}^{-1}, \mathrm{pH} 4.0$ and $v=30 \mathrm{mV} \mathrm{s}^{-1}$.

In addition to the good sensitivity, a suitable reproducibility and response stability is required for an electrochemical sensing device. In this regard, the electrodes were submitted to consecutive redox cycles in the presence of DA (Figure S5). It was observed that the voltammetric profile remained nearly constant (the faradaic currents and potential values did not change significantly). It is also important to note that no fouling effect (caused by DA adsorption) was observed for the carbon paste electrodes, even after 100 cycles. This contrasts with the behavior observed for Pt electrodes, in which a blocking of the signal due to DA adsorption on the electrodic surface was observed.

To confirm that DA oxidation occurred via an electrocatalytical process when the modified electrodes were employed, the dependence of Ipa/ $\mathrm{n}^{1 / 2}$ on scan rate was plotted, as shown in Figure 4. According to Nicholson [41], a non-linear relationship of the $I p a / n^{1 / 2} v s v$ plot exhibited the typical behavior of a typical electrochemical-chemical catalytic process, as observed for the electrodes containing KP20 and KPy20. 

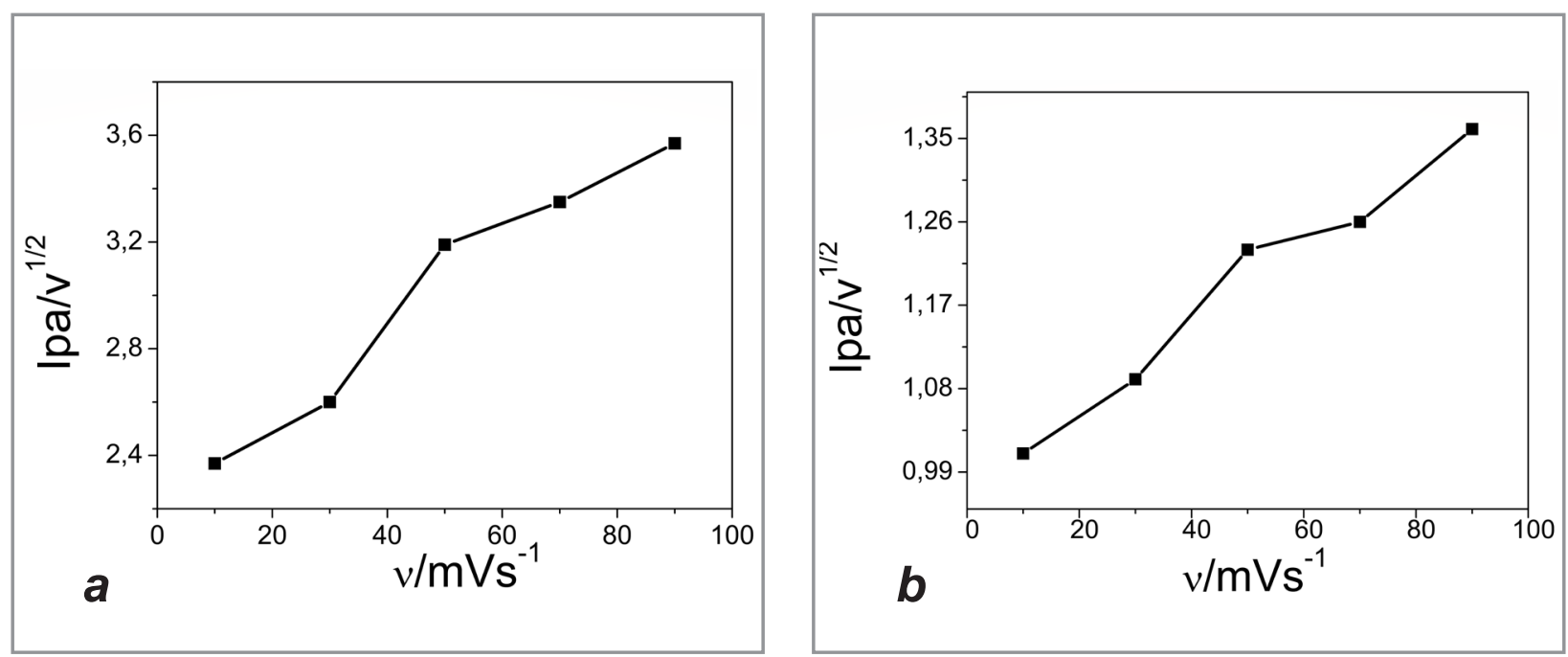

Figure 4. Plot of $\mathrm{Ip} / v^{1 / 2}$ against scan rate $(v)$ for $\mathrm{DA}\left(50 \mu \mathrm{mol} \mathrm{L}^{-1}\right)$ at the modified electrodes a) KPPE and b) KPyPE. Supporting electrolyte: $\mathrm{NaCl} 0.5 \mathrm{~mol} \mathrm{~L}^{-1}$ and $\mathrm{pH} 4.0$.

\section{Electrochemical oxidation of ascorbic acid as a possible interferent for DA detection}

The electrochemical response of the electrodes in the presence of ascorbic acid (AA) was evaluated due to its possible interference for physiological DA detection. AA is present along with DA in biological fluids, and its presence considerably decreases the sensitivity of most of the materials used in electrochemical sensors for DA determination [2,52-53]. This is due to the fact that the redox process of AA occurs at potentials that are close to those observed for DA oxidation [50,54].

Figure 5.a displays the cyclic voltammograms of the modified and unmodified Eeonomer ${ }^{\circledR}$ (KPPE,

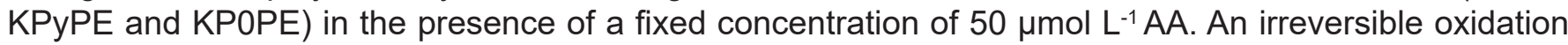
peak was observed for KPOPE at Epa of ca. $450 \mathrm{mV}$, however, the voltammetric response for the KPPE and KPyPE showed no oxidation processes or just a small anodic peak. This is a particularly important finding for the production of selective sensors for DA quantification, due to the possibility of identification of this analyte in different complex samples. The cyclic voltammogram for the KPPE in the presence of AA is highlighted as an insert in Figure 5.a due to the high capacitive current presented by this material. For comparison, Figure 5.b shows the electrochemical behavior of the electrodes CNTPE, GRPE and KPOPE in the presence of AA. For those carbonaceous materials, it is possible to observe the same oxidation process as for the KPOPE, with a higher current peak for the GRPE, similarly to the response obtained in presence of DA. 

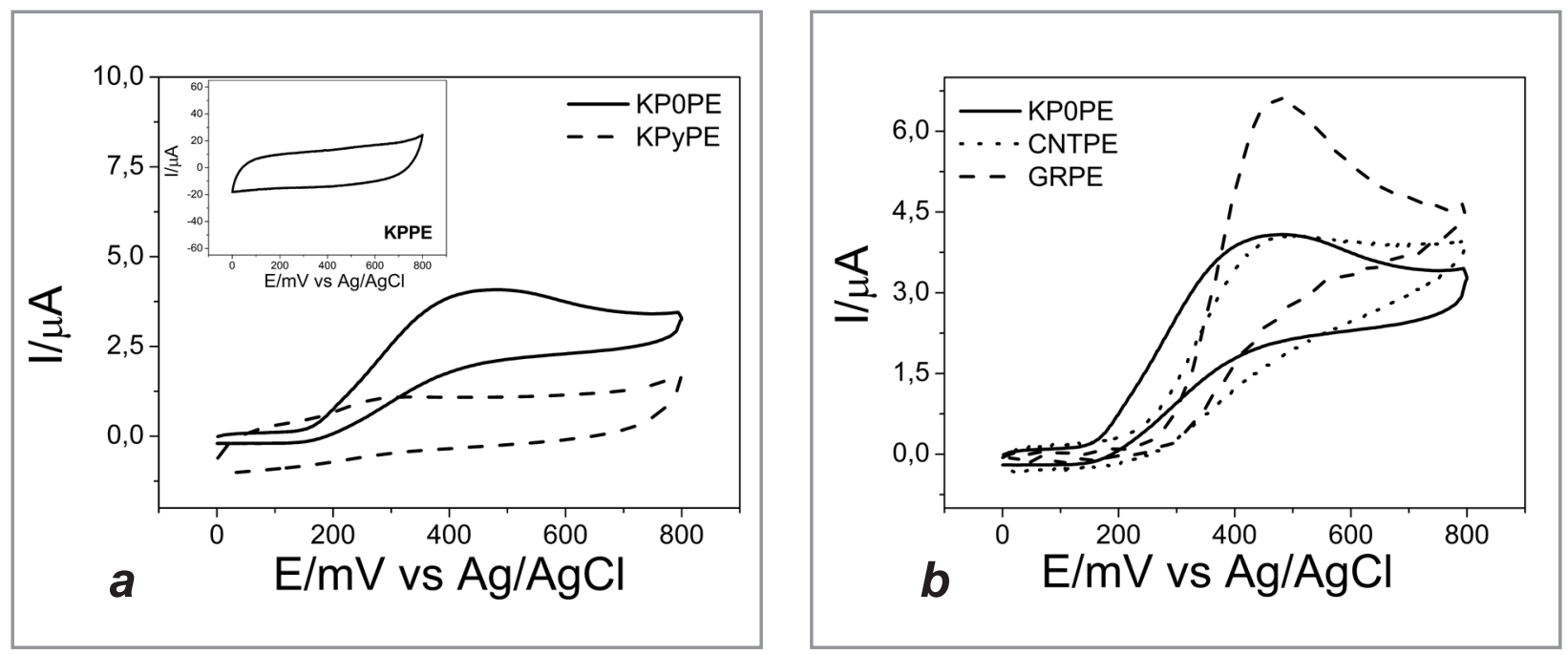

Figure 5. Cyclic voltammograms of a) KPOPE, KPPE and KPyPE and $\boldsymbol{b}$ ) KPOPE, GRPE and CNTPE in presence of AA in a concentration of $50 \mu \mathrm{mol} \mathrm{L}^{-1}$. Conditions: $\mathrm{NaCl} 0.5 \mathrm{~mol} \mathrm{~L}^{-1}, \mathrm{pH} 4.0$ and $\nu=30 \mathrm{mV} \mathrm{s}^{-1}$.

The obtained results indicate that the use of KPOPE, GRPE and mainly CNTPE electrodes are not suitable for the use in DA quantification in samples where AA is also present (S6). On the other hand, KPPE and KPyPE electrodes are both selective to DA determination, which is a desirable and important feature for applications in biological samples.

The information described above has showed that KP20 materials have the best performance regarding the application in the preparation of electrochemical sensors. Aiming to produce a proof of concept for the statement presented above, the quantification of DA in a commercial sample was performed by using cyclic voltammetry and standard addition methodology. The KPPE was chosen for this study due to its better sensitivity $\left(0.11 \mathrm{~A} \mathrm{~mol}^{-1} \mathrm{~L}\right)$ for DA determination. Figure 6 shows the standard addition curve used for DA quantification. The relationship obtained between Ipa $(\mu \mathrm{A})$ and DA concentration $\left(\mu \mathrm{mol} \mathrm{L}^{-1}\right)$ was obtained by linear regression (Ipa $=10.23+0.21[\mathrm{DA}], \mathrm{R}=0.99773)$ and the determination of DA concentration in the sample was obtained by extrapolation to Ipa $=0$. The obtained value, $50.8 \mu \mathrm{mol} \mathrm{L}^{-1}$, agrees with the labeled concentration of DA in the tested commercial injection solution sample $\left(50.4 \mu \mathrm{mol} \mathrm{L}^{-1}\right)$.

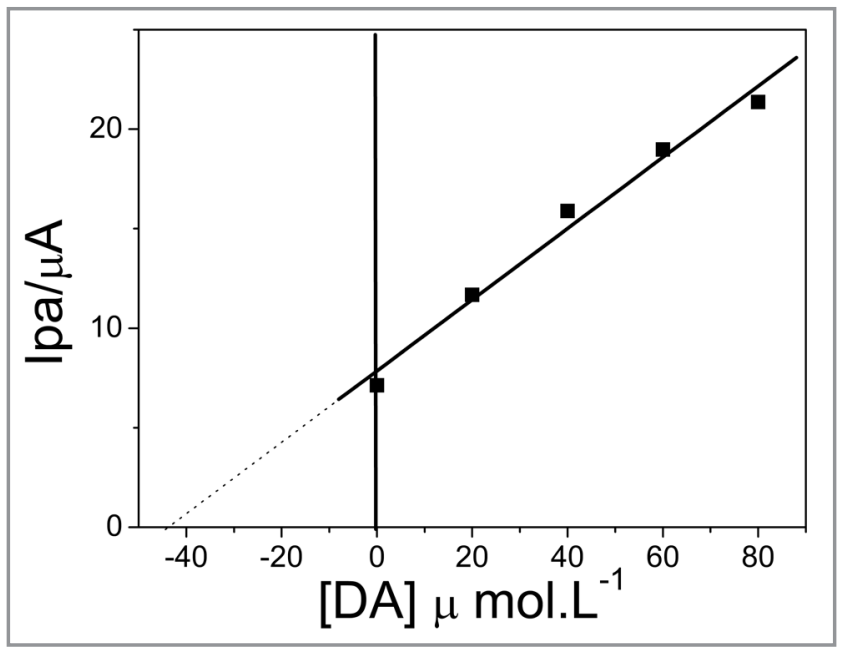

Figure 6. Ipa vs DA concentration plot obtained for the standard addition methodology aiming DA quantification in a commercial injection solution. Ipa values were obtained by using cyclic voltammetry and KPPE electrode in the following conditions: supporting electrolyte: $\mathrm{NaCl} 0.5 \mathrm{~mol} \mathrm{~L}^{-1}, \mathrm{pH} 4.0$ and $v=30 \mathrm{mV} \mathrm{s}^{-1}$. 


\section{Factorial Design}

Intending to verify whether the combination of the two modified Eeonomers ${ }^{\circledR}$ could enhance the electrochemical response for DA detection, since both materials presented were able to electrocatalyze this process, a $3^{2}$ full factorial design was performed including the mixture of KP20 and KPy20 materials for CPE construction, in different proportions, as one of the variables. The chosen second variable was $\mathrm{pH}$ due to the importance of this parameter in doping the conducting polymers present in the system.

Cyclic voltammograms acquired with the electrodes containing the Eeonomers ${ }^{\circledR}$ KP20 (KPPE), KPy20 (KPyPE), and a mixture of both (KP20/KPy20 50:50 w/w) in acetate buffer at pHs 3.0, 5.0 and 7.0 showed only capacitive currents. The electrochemical response of the electrodes toward AA oxidation revealed the great potential of the modified KPPE and KPyPE electrodes for DA detection, since the KPPE electrode did not show current peaks in the presence of AA, and the KPyPE could detect AA only at concentrations higher than $20 \mu \mathrm{mol} \mathrm{L}{ }^{-1}$. Thus, the Eeonomers ${ }^{\circledR}(\mathrm{KP} 20$ and KPy20) are highly selective to DA even in the presence of its principal interferent (AA) in physiological medium.

The current results obtained in each assay of the $3^{2}$ full factorial are displayed in the Table III. A central point assayed in triplicate was included in the factorial design for standard deviation estimate.

Table III. Current results obtained in each assay of the $3^{2}$ full factorial design to investigate the influence of electrode composition and $\mathrm{pH}$ on the sensing capabilities of the developed devices

\begin{tabular}{cccc}
\hline Assay & pH & CPE composition & Ipa $(\mu \mathrm{A})$ \\
\hline 1 & $-(3.0)$ & $-(\mathrm{KP} 20)$ & 28.3 \\
2 & $+(7.0)$ & $-(\mathrm{KP} 20)$ & 15.2 \\
3 & $-(3.0)$ & $+(\mathrm{KPy} 20)$ & 6.64 \\
4 & $+(7.0)$ & $+(\mathrm{KPy} 20)$ & 9.31 \\
5 & $0(5.0)$ & $0(\mathrm{KP} 20 / \mathrm{KPy} 20)$ & 24.3 \\
6 & $0(5.0)$ & $0(\mathrm{KP} 20 / \mathrm{KPy} 20)$ & 24.0 \\
7 & $0(5.0)$ & $0(\mathrm{KP} 20 / \mathrm{KPy} 20)$ & 25.4 \\
8 & $0(5.0)$ & $-(\mathrm{KP} 20)$ & 25.1 \\
9 & $+(7.0)$ & $0(\mathrm{KP} 20 / \mathrm{KPy} 20)$ & 20.4 \\
10 & $0(5.0)$ & $+(\mathrm{KPy} 20)$ & 7.82 \\
11 & $-(3.0)$ & $0($ KP20/KPy20 $)$ & 22.0 \\
\hline
\end{tabular}

The main effects $(\mathrm{pH}=-5.18$ and CPE composition $=-13.8)$ indicated that both variables significantly affect the evaluated response. However, a significant interaction effect ( $\mathrm{pH}$ vs CPE composition $=+7.85$ ) is also observed, which implies in a non-homogeneous effect of $\mathrm{pH}$ for both electrodes. For KPPE electrode, the $\mathrm{pH}$ effect reduces the Ipa 13.1 times, while for the KPyPE a 2.67- $\mathrm{AA}$ increase in the Ipa was observed. This interaction effect and the significant overall curvature of the response $\left(\bar{y}_{f}-\bar{y}_{c}=-9.71\right.$ units, obtained by difference between the mean of the points of the $3^{2}$ factorial and the mean at the center of the design) indicate that the first-degree equation is inadequate to represent the local response surface. The latter shows the need for construction of a quadratic response surface, a model that was evaluated by Analysis of Variance - ANOVA (Table IV). 
Table IV. Analysis of Variance for the quadratic adjusted model (Ipa $=24.2-2.00 \mathrm{pH}-7.47 \mathrm{EPC}$ $\left.-2.44 \mathrm{pH}^{2}-7.18 \mathrm{EPC}^{2}+3.94 \mathrm{pH} \times \mathrm{EPC}\right)$

\begin{tabular}{lcccc}
\hline Source & $\begin{array}{c}\text { Sum of Squares } \\
\text { (SS) }\end{array}$ & $\begin{array}{c}\text { Degrees of } \\
\text { Freedom }\end{array}$ & $\begin{array}{c}\text { Mean of Squares } \\
\text { (MS) }\end{array}$ & F-test \\
\hline Regression (R) & 603.27 & 5 & 120.65 & 52.39 \\
Residual (r) & 11.51 & 5 & 2.31 & \\
Lack of Fit (LF) & 10.43 & 3 & 3.48 & 6.40 \\
Pure Error (PE) & 1.09 & 2 & 0.54 & \\
Total & 614.78 & 10 & & \\
\hline
\end{tabular}

$\%$ Total Explained Variance $=98.13$

$\%$ Explained Variance Maximum $=99.82$

ANOVA shows that the response surface satisfactorily describes the set of results in the studied range for the factors. Table IV showed that the model could explain $98.13 \%$ of the variability in the data. This value is very close to the maximum variance that could be explained (99.82\%). The $F=\mathrm{MS}_{\mathrm{R}} / \mathrm{MS}_{\mathrm{r}}=52.39$ $>>F_{5,5,95 \%}=5.05$, indicating that the regression is significant. $F_{\mathrm{LF}}=\mathrm{MS}_{\mathrm{LF}} / \mathrm{MS}_{\mathrm{pe}}=6.40<F_{3,2,95 \%}=19$, shows that there is no significant lack of fit in the quadratic model. Finally, the random distribution of the residues indicates the suitability of the model, as showed in the inset of Figure 7 . Figure 7 shows the tridimensional plot of the model equation, which displays a plateau region where the Ipa maximum $(28.3 \mu \mathrm{A})$ can be obtained using the $\mathrm{pH}$ close to 3.0 and KP20 as EPC. Regarding the determination of DA in biological samples ( $\mathrm{pH} \sim 7.0$ ), it can be performed with EPC/Kp20/KPy20 (Ipa = 20.4 $\mu \mathrm{A})$. Therefore, this result shows the correct choice of factors, $\mathrm{pH}$ and electrode composition for the quantification of this neurotransmitter.

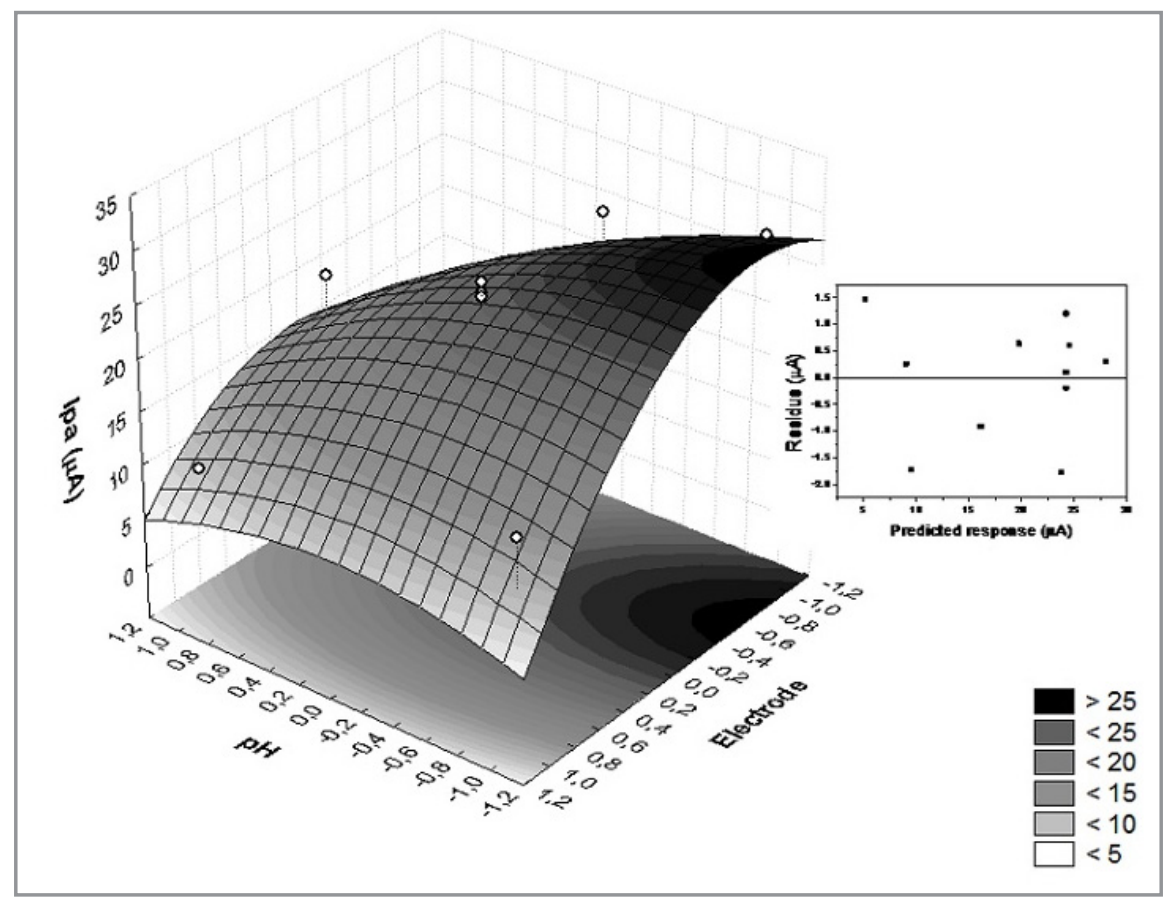

Figure 7. Response surface of the model (Ipa $=24.2-2.00 \mathrm{pH}-7.47 \mathrm{EPC}$ $\left.2.44 \mathrm{pH}^{2}-7.18 \mathrm{EPC}^{2}+3.94 \mathrm{pH} \times \mathrm{EPC}\right)$. 


\section{CONCLUSIONS}

Eonomers $^{\circledR}$ materials, prepared by incorporation of conducting polymers (Pani (KP20) and PPy (KPy20)) on CB, were used to prepare CPEs for the first time. These modified CPEs were investigated as candidates as electrochemical sensors for DA detection in commercial drugs. Other carbon allotropes such as GR, pristine CB (KP0) and MWCNT were also applied on CPE construction and those electrodes were evaluated toward DA detection for comparison.

The best DA detection performance was verified for CPE prepared with the KP20 Eonomer ${ }^{\circledR}$ with a sensitivity of $0.110 \mathrm{~A} \mathrm{~mol}^{-1} \mathrm{~L}$ at $\mathrm{pH}$ 4. The CPE prepared with KP20 doubled the sensitivity verified for the CPE produced with MWCNT. Besides the promising detection capacity, the prepared CPEs have presented good response stability in the presence of DA. The good analytical features of KP20 CPE enabled its successful application to detect DA in a commercial formulation.

The developed CPE were also tested in the presence of AA, since this compound is one of the most important interfering species for DA detection in physiological matrices. Both Eonomers ${ }^{\circledR}$-based CPE showed to be selective, and no significant influence on DA determination was observed.

The response surface obtained after performing the $3^{2}$ factorial design showed that DA voltammetric signal can be improved using the KP20 CPE at pH 3.0. However, even with lower sensitivity, the DA determination in commercial samples can also be carried out with the KP20/KPy20 (50:50 w/w) electrode at $\mathrm{pH}$ of 7.0, which represents a more suitable condition for the analysis of biological samples. These results showed that the electroactive modifiers (Pani and PPy) provide electrocatalytic properties for the electrodes, enhancing their electrochemical detection capabilities. Thus, our findings clearly suggest that the developed electrochemical devices can found promising applications to perform fast, cheap and sensitive determinations of DA in real samples.

\section{Conflicts of interest}

We hereby declare no financial conflicts of interest related with the information described in this text.

\section{Acknowledgements}

The authors would like to acknowledge the financial support from the following Brazilian Funding Agency: National Council for Scientific and Technological Development (CNPq), especially through the Program INCT-2014: Organic Electronic (INEO - acronym in Portuguese), [Grant n0 14/50869-6]; the financial support from Fundação Araucária (Paraná State) and Coordination for the Improvement of Higher Education Personnel (CAPES).

\section{REFERENCES}

1. Adams, R. N. Anal. Chem., 1958, 30 (9), p 1576 (https://doi.org/10.1021/ac60141a600).

2. Gnahore, G. T.; Velasco-Torrijos, T.; Colleran, J. Electrocatalysis, 2017, 8, pp $459-471$ (https://doi. org/10.1007/s12678-017-0402-x).

3. Matt, S. B.; Manjunatha, S.; Manjunatha, S.; Sidlingappa, D. M.; Sidlingappa, M. ChemistrySelect, 2019, 4 (19), pp 5839-5844 (https://doi.org/10.1002/slct.201900642).

4. Naik, T. S. S. K.; Mwaurah, M. M.; Swamy, B. E. K. J. Electroanal. Chem., 2019, 834 (1), pp 71-78 (https://doi.org/10.1016/j.jelechem.2018.12.054).

5. Tajik, S.; Beitollahi, H.; Nejad, F. G.; Safaei, M.; Zhang, K.; Le, Q. V.; Varma, R. S.; Jang, H. W.; Shokouhimehr, M. RSC Adv., 2020, 10, pp 21561-21581 (https://doi.org/10.1039/d0ra03672b).

6. Lopes, L. C.; Lima, D.; Mendes Hacke, A. C.; Schveigert, B. S.; Calaça, G. N.; Simas, F. F.; Pereira, R. P.; lacomini, M.; Viana, A. G.; Pessôa, C. A. Talanta, 2020, 121634 (https://doi.org/10.1016/j. talanta.2020.121634).

7. Švancara, I.; Kalcher, K.; Walcarius, A.; Vytras, K. Electroanalysis with carbon paste electrodes, CRC Pres, New York, 2012.

8. Rajaei, M.; Foroughi, M. M.; Jahani, S.; Zandi, M. S.; Nadiki, H. H. J. Mol. Liq., 2019 (https://doi. org/10.1016/j.molliq.2019.03.135). 
9. Pokhrel, L. R.; Ettore, N.; Jacobs, Z. L.; Zarr, A.; Weir, M. H.; Scheuerman, P. R.; Kanel, S. R.; Dubey, B. Sci. Total Environ., 2017, 574, pp 1379-1388 (https://doi.org/10.1016/j.scitotenv.2016.08.055).

10. Oularbi, L.; Turmine, M.; Salih, F. E.; El Rhazi, M. J. Environ. Chem. Eng., 2020, 103774 (https://doi. org/10.1016/j.jece.2020.103774).

11. Zaidi, S. A. Int. J. Electrochem. Sci., 2013, 8, pp 11337-11355.

12. Kalambate, P. K.; Rawool, C. R.; Srivastava, A. K. New J. Chem., 2017, 41 (15), pp 7061-7072 (https:// doi.org/10.1039/c7nj00101k).

13. Yang, Z.; Tian, J.; Yin, Z.; Cui, C.; Qian, W.; Wei, F. Carbon, 2019, 141, pp 467-480 (https://doi. org/10.1016/j.carbon.2018.10.010).

14. Seman, R. N. A. R.; Azam, M. A.; Mohamad, A. A. Renewable Sustainable Energy Rev., 2017, 75, pp 644-659 (https://doi.org/10.1016/j.rser.2016.10.078).

15. Wildgoose, G. G.; Banks, C. E.; Leventis, H. C.; Compton, R. G. Microchim. Acta, 2006, 152, pp 187-214 (https://doi.org/10.1007/s00604-005-0449-x).

16. Li, C.; Thostenson, E. T.; Chou, T. W. Compos. Sci. Technol., 2008, 68 (6), pp 1227-1249 (https://doi. org/10.1016/j.compscitech.2008.01.006).

17. Oliveira, T. M. B. F.; Morais, M. Appl. Sci., 2018, 8, 1925 (https://doi.org/10.3390/app8101925)

18. Kumar, V.; Lee, G.; Monika; Choi, J.; Lee, D. J. Polymer, 2020, 190 (2), 122221 (https://doi.org/10.1016/j. polymer.2020.122221).

19. Pumera, M. Chem. Eur. J., 2009, 15, pp 4970-4978 (https://doi.org/10.1002/chem.200900421).

20. Mazloum-Ardakani, M.; Beitollahi, H.; Ganipour, B.; Naeimi, H.; Nejati, M. Bioelectrochemistry, 2009, 75 (1), pp 1-8 (https://doi.org/10.1016/j.bioelechem.2008.11.006).

21. Afshar, S.; Zamani, H. A.; Maleh, H. K. J. Pharm. Biomed. Anal., 2020, 188, 113393 (https://doi. org/10.1016/j.jpba.2020.113393).

22. Bijad, M.; Maleh, H. K.; Farsi, M.; Shahidi, S. A. Food Anal. Meth., 2017, 10, pp 3773-3780 (https://doi. org/10.1007/s12161-017-0933-z).

23. Valentini, F.; Amine, A.; Orlanducci, S.; Terranova, M. L.; Palleschi, G. Anal. Chem., 2003, 75 (20), pp 5413-5421 (https://doi.org/10.1021/ac0300237).

24. Khodabakhshi, S.; Fulvio, P. F.; Andreoli, E. Carbon, 2020, 162, pp 604-649 (https://doi.org/10.1016/j. carbon.2020.02.058).

25. Arduini, F.; Cinti, S.; Mazzaracchio, V.; Scognamiglio, V.; Amine, A.; Moscone, D. Biosens. Bioelectron, 2020, 156, 112033 (https://doi.org/10.1016/j.bios.2020.112033).

26. Vicentini, F. C.; Ravanini, A. E.; Figueiredo-Filho, L. C.; Iniesta, J.; Banks, C. E.; Fatibello-Filho, O. Electrochim. Acta, 2015, 157, pp 125-133.

27. Cabral, M. F.; Pedrosa, V. A.; Suffredini, H. B.; Moreno, R. B.; Mattoso, L. H.; Gonçalves, P. S.; Machado, S. A. S. Zaštita Materijala, 2006, 47 (4), pp 41-45.

28. Liu, X.; Liu, J. View, 2021, 2 (1), 20200102 (https://doi.org/10.1002/VIW.20200102).

29. Siddeeg, S. M. Int. J. Electrochem. Sci, 2020, 15, pp 599-612 (https://doi.org/10.20964/2020.01.61).

30. Beitollahi, H.; Safaei, M.; Tajik, S. Anal. Bioanal. Chem. Res., 2019, 6 (1), pp $81-96$ (https://doi. org/10.22036/ABCR.2018.142219.1229).

31. Matysik, F. M. Anal. Bioanal. Chem., 2003, 375, pp 33-35 (https://doi.org/10.1007/s00216-002-1635-x).

32. Barragan, J. T. C.; Kubota, L. T. Electrochim. Acta, 2020, 341, 136048 (https://doi.org/10.1016/j. electacta.2020.136048).

33. Deroco, P. B.; Fatibello Filho, O.; Arduini, F.; Moscone, D. Electroanalysis, 2019, 31 (11), pp 21452154 (https://doi.org/10.1002/elan.201900042).

34. Li, Y. Y.; Kang, P.; Wang, S. Q.; Liu, Z. G.; Li, Y. X.; Guo, Z. Sensors and Actuators, 2021, 327, 128878 (https://doi.org/10.1016/j.snb.2020.128878).

35. Sajid, M.; Nazal, M. K.; Mansha, M.; Alsharaa, A.; Jillani, S. M. S.; Basheer, C. TrAC, Trends Anal. Chem., 2016, 76, pp 15-29 (https://doi.org/10.1016/j.trac.2015.09.006).

36. Mosleh, M.; Ghoreishi, S. M.; Masoum, S.; Khoobi, A. Sens. Actuators, B, 2018, 272, pp 605-611 (https://doi.org/10.1016/j.snb.2018.05.172). 
37. Cuéllar, M.; Pfaffen, V.; Ortiz, P. I. J. Electroanal. Chem., 2016, 765, pp 37-44 (https://doi.org/10.1016/j. jelechem.2015.07.050).

38. Varol, T. O.; Perk, B.; Avci, O.; Hakli, O.; Xue, C.; Li, Q.; Anik, U. Measurement, 2019, 147, 106867 (https://doi.org/10.1016/j.measurement.2019.106867).

39. Zhao, G.; Wang, H.; Liu, G.; Wang, Z. Sens. Actuators, B, 2016, 235, pp 67-73 (https://doi.org/10.1016/j. snb.2016.05.051).

40. Avlyanov, J. K. Synth. Met., 1999, 102 (1-3), pp 1272-1273 (https://doi.org/10.1016/S03796779(98)01468-4).

41. Domenech, S. C.; Bendo, L.; Mattos, D. J. S.; Borges Jr., N. G.; Zucolotto, V.; Mattoso, L. H. C.; Soldi, V. Polym. Compos., 2009, 30 (7), pp 897-906 (https://doi.org/10.1002/pc.20630).

42. Zucolotto, V.; Avlyanov, J.; Gregório Jr., R.; Mattoso, L. H. C. J. Appl. Polym. Sci., 2004, 94 (2), pp 553-557 (https://doi.org/10.1002/app.20952).

43. Zucolotto, V.; Avlyanov, J.; Mattoso, L. H. C. Polym. Compos., 2004, 25 (6), pp 617-621 (https://doi. org/10.1002/pc.20056).

44. Malha, S. I. R.; Mandli, J.; Ourari, A.; Amine, A. Electroanal., 2013, 25, pp 2289-2297 (https://doi. org/10.1002/elan.201300257).

45. Zhou, H.; Chen, H.; Luo, S.; Lu, G.; Wei, W.; Kuang, Y. J. Solid. State Electrochem., 2005, 9, pp 574580 (https://doi.org/10.1007/s10008-004-0594-x).

46. Blinova, N. V.; Stejskal, J.; Trchová, M.; Prokes`, J.; Omastová, M. Eur. Polym. J., 2007, 43, pp 23312341 (https://doi.org/10.1016/j.eurpolymj.2007.03.045).

47. Hawley, M. D.; Tatawawa, S. V.; Piekarsk, S.; Adams, R. N. J. Anal. Chem. Soc, 1967, 89 (2), pp 447450.

48. Bacil, R. P.; Chen, L.; Serrano, S. H. P.; Compton, R. G. Phys. Chem. Chem. Phys., 2020, 22, pp 607614 (https://doi.org/10.1039/C9CP05527D).

49. Schindler, S.; Bechtold, T. J. Electroanal. Chem., 2019, 836, pp 94-101 (https://doi.org/10.1016/j. jelechem.2019.01.069).

50. Siqueira Jr, J. R.; Gasparotto, L. H. S.; Crespilho, F. N.; Carvalho, A. J. F.; Zucolotto, V.; Oliveira Jr, O. N. J. Physical. Chem. B, 2006, 110 (45), pp 22690-22694 (https://doi.org/10.1021/jp0649089).

51. Brett, A. M. O.; Brett, M. A. Eletroquímica: princípios, métodos e aplicações. Livraria Almedina, Coimbra, 1996.

52. Santos, P. M.; Sandrino, B.; Moreira, T. F.; Wohnrath, K.; Nagata, N.; Pessoa, C. A. J. Braz. Chem. Soc., 2007, 18 (1), pp 93-99 (https://dx.doi.org/10.1590/S0103-50532007000100010).

53. Kim, D. S.; Kang, E. S.; Baek, S.; Choo, S. S.; Chung, Y. H.; Lee, D.; Min, J.; Kim, T. H. Sci. Rep., 2018, 8, 14049 (https://doi.org/10.1038/s41598-018-32477-0).

54. Cheng, J.; Wang, X.; Nie, T.; Yin, L.; Wang, S.; Zhao, Y.; Wu, H.; Mei, H. Anal. Bioanal. Chem., 2020, 412, pp 2433-2441 (https://doi.org/10.1007/s00216-020-02455-5). 


\section{SUPPORTING INFORMATION}

S1 - Scanning Electron Microscopy (SEM) Morphological analysis of pristine Eeonomers ${ }^{\circledR}$ by SEM were performed on a LEICA / Stereoscan - 440 equipment and also on Zeiss equipment - DSM 960. All composites were cryogenically fractured and analyzed in the fracture region. The studies on the morphology of composites aimed to dispersion analysis of Eeonomers $₫$ particles in the elastomeric matrix (SEBS). SEM analyzes were performed for pure Eeonomers ${ }^{\circledR}$ (in powder) and in films of cryogenically fractured composites.
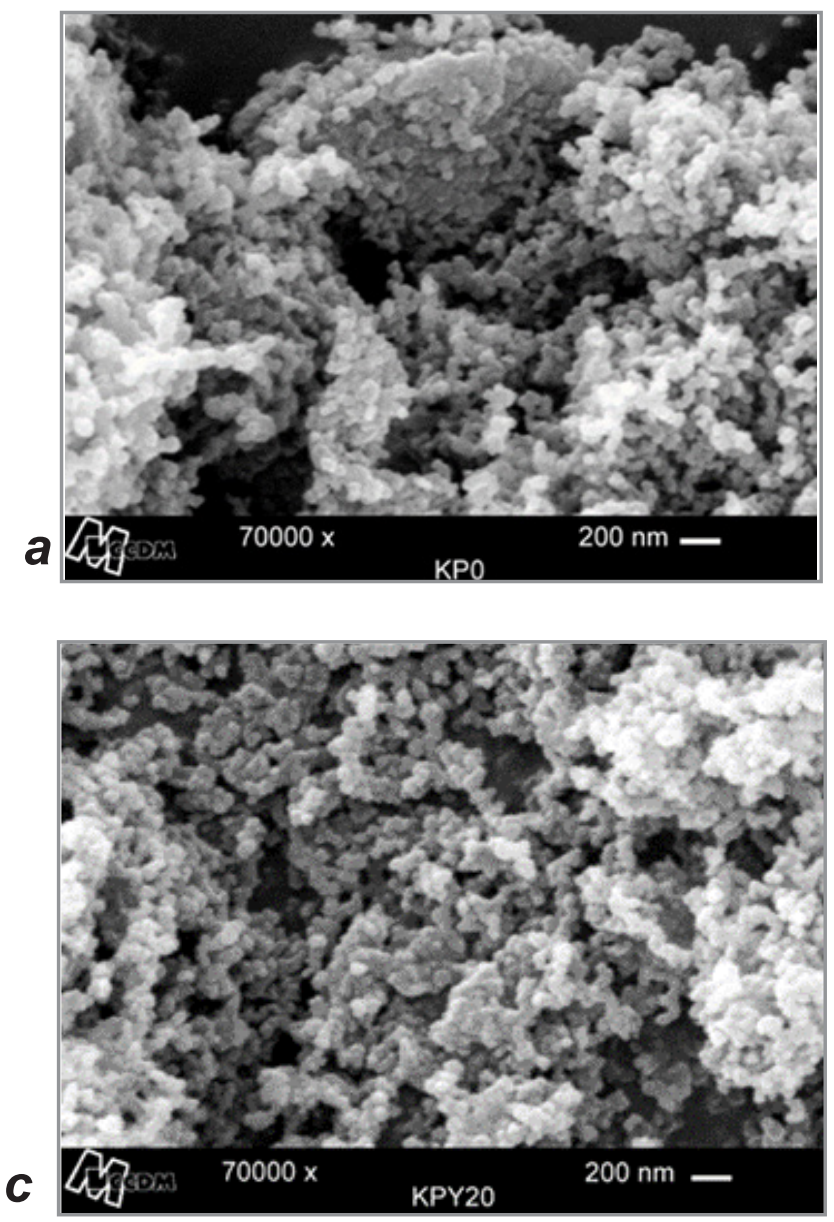

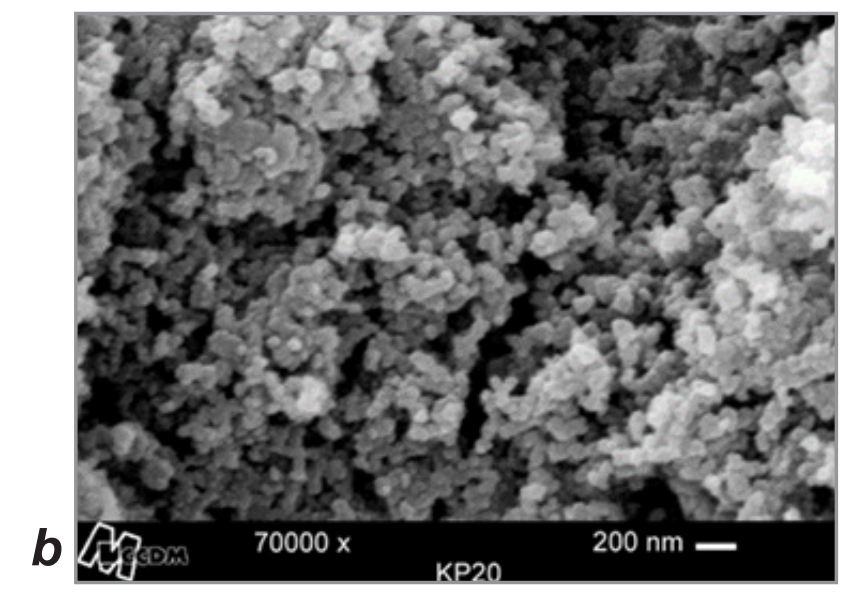

Figure S1. (a) Photomicrographs obtained by SEM from the Eeonomer® KP0 (a); KP20 (b) and KPy (c). Increase at 70000x.

S2 - Eonix Co provides Eeonomers ${ }^{\circledR}$ compounds in a fix proportion of conducting polymers, such as $3,5,20,40,60,200 \%$. Consequently, in this work the effects of the amount of conductive polymer on the electrochemical signals of dopamine at the carbon black electrode in the presence and absence of ascorbic acid were examined. With a low proportion of Pani or PPy, the carbon black powder is free to conduct an electric current. Since when the material contains a high proportion of polymer in its composition, the carbon black is prevented from conducting an electric current by thick layers of polymer, the which are hardly doped. Therefore, in the cyclic voltammograms performed at $\mathrm{pH}=1.0$ of $\mathrm{KP} 3.5$ (3.5\% PANI), faradaic currents related to the redox processes of chemical doping of polyaniline in the emerald state can be observed, promoting an increase in conductivity. At KP20 (20\% PANI) only an increase in capacitive current is observed and at KP40 (40\% PANI), a resistive profile can be observed in addition to the capacitive current. Due to these electrochemical behaviors, KP20 was chosen to be investigated in EPC. 

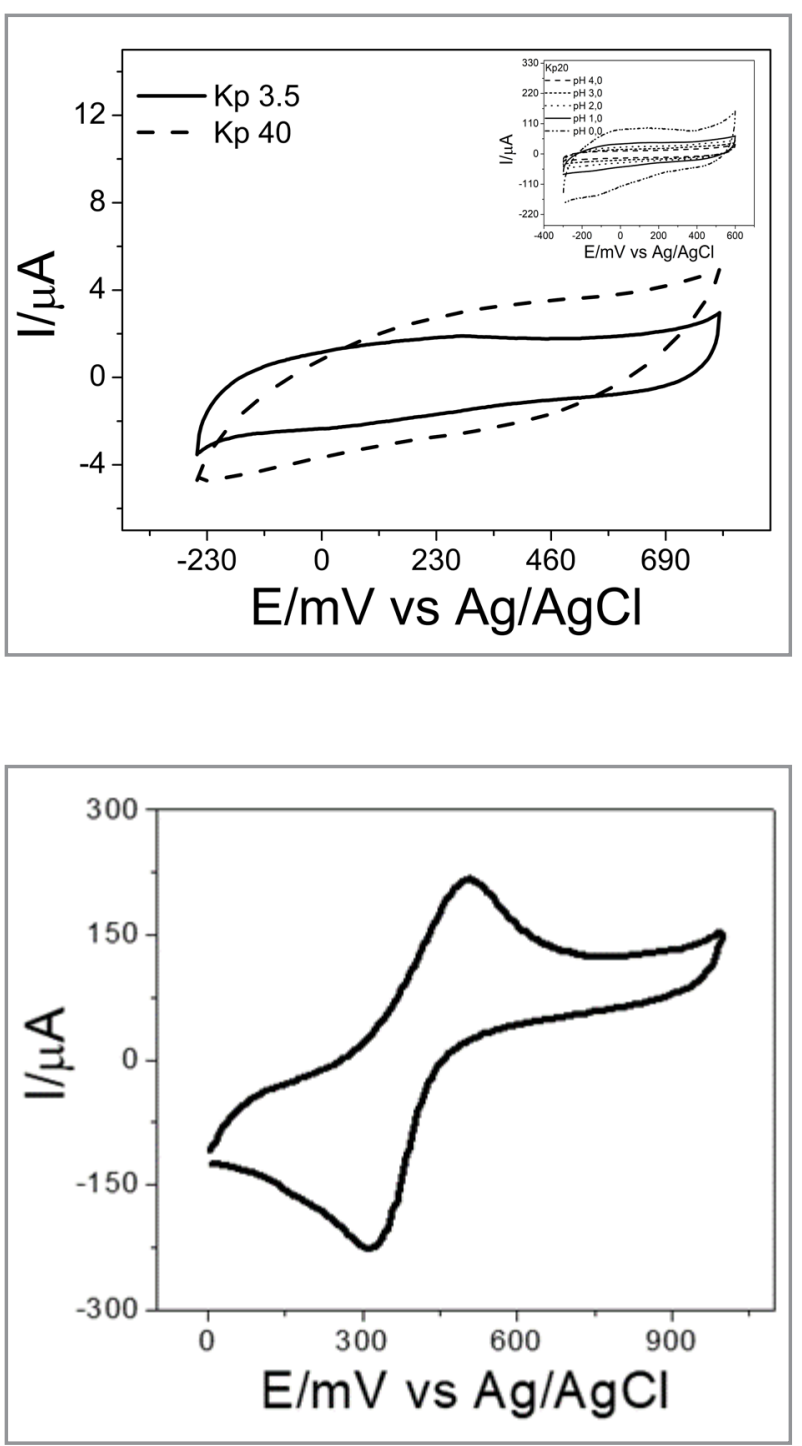

Figure S2. Cyclic voltammograms for CPE/KP3.5 and CPE/ $\mathrm{KP} 40$ at $30 \mathrm{mV} \mathrm{s}^{-1}$ scan rate. Supporting electrolyte: $\mathrm{NaCl} 0.5$ $\mathrm{mol} \mathrm{L}^{-1}$ at $\mathrm{pH} 1.0$. Inset: cyclic voltammograms of CPE/KP20 in different $\mathrm{pH}(0-4.0)$.

S3 -The oxidation of DA on a Pt electrode occurred at higher potentials $(\mathrm{Epa}=504 \mathrm{mV})$ in relation to electrodes modified with polymers (Kp20 and Kpy20). Another disadvantage on the use of $\mathrm{Pt}$ electrode is that DA adsorbs on the surface of this metal, which may lead to a fouling effect.

Figure S3. Cyclic voltammogram for the Pt electrode in 6,0 mmol. $\mathrm{L}^{-1}$ of DA. Supporting electrolyte: $\mathrm{NaCl} 0.5 \mathrm{~mol} \mathrm{~L}^{-1}, \mathrm{pH}$ 4.0 and $v=30 \mathrm{mV} \mathrm{s}^{-1}$.

S4 - We observed that oxidation of DA on a Pt electrode occurred at higher potentials $(\mathrm{Epa}=504 \mathrm{mV})$. Another disadvantage on the use of Pt electrode is that DA adsorbs on the surface of this metal, which may lead to a fouling effect.
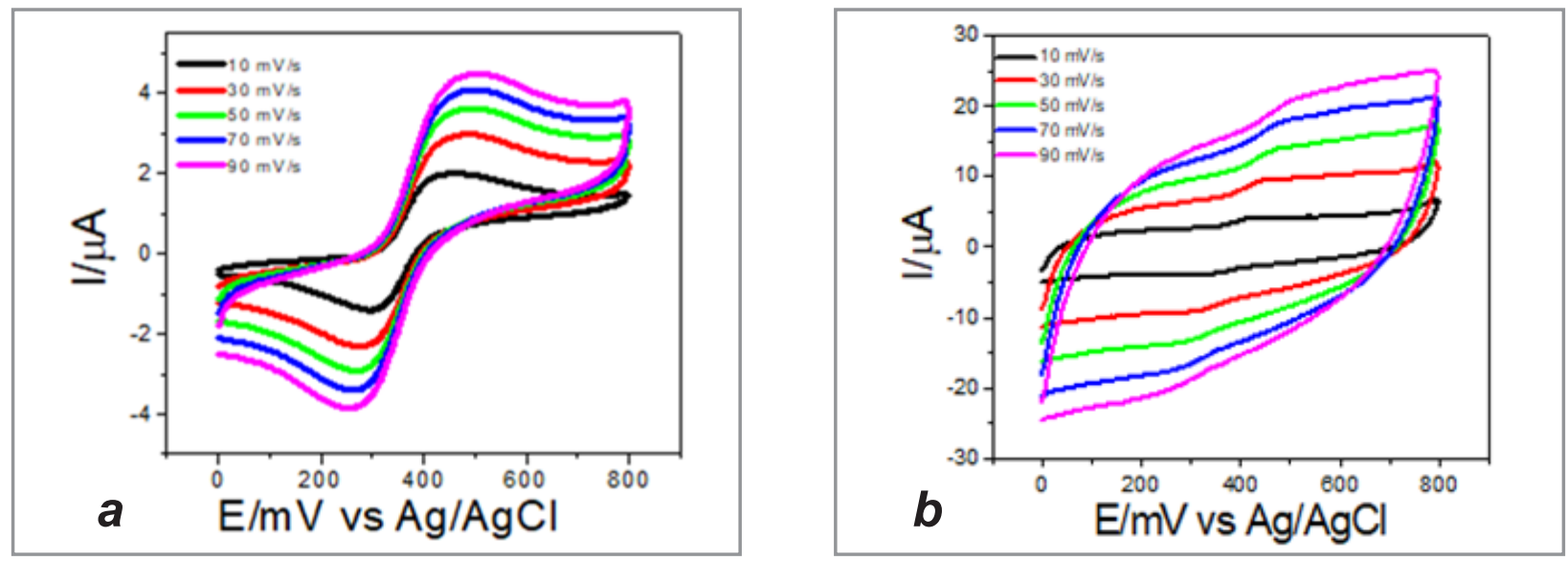

Figure S4. Cyclic voltammograms for the $\operatorname{KPOPE}(\boldsymbol{a}), \operatorname{KPPE}(\boldsymbol{b}), \operatorname{KPyPE}(\boldsymbol{c})$ in $50 \mu \mathrm{mol} \mathrm{L}^{-1}$ of DA. Supporting electrolyte: $\mathrm{NaCl} 0.5 \mathrm{~mol} \mathrm{~L}^{-1}, \mathrm{pH} 4.0$ and $v=10,30,50.70$ and $90 \mathrm{mV} \mathrm{s}^{-1}$. 


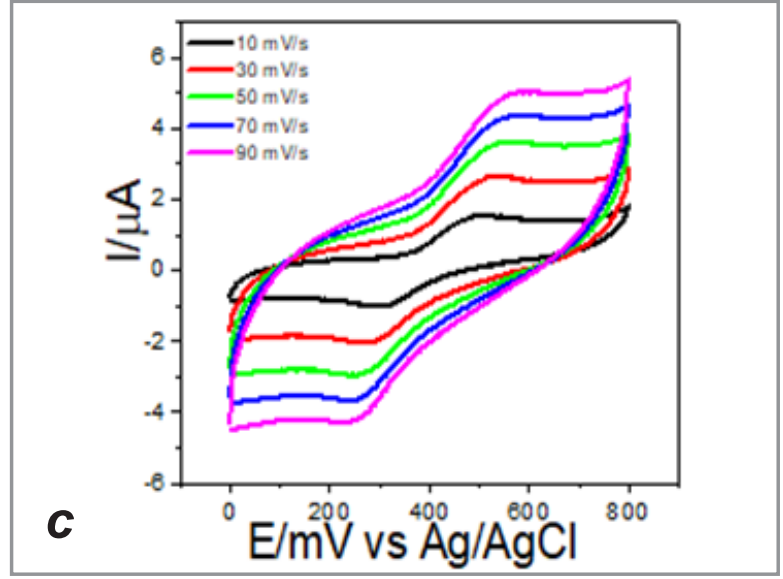

Figure S4 continuation. Cyclic voltammograms for the

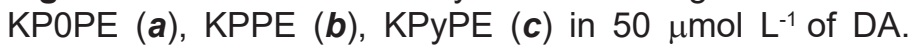
Supporting electrolyte: $\mathrm{NaCl} 0.5 \mathrm{~mol} \mathrm{~L}^{-1}, \mathrm{pH} 4.0$ and $v=10$, $30,50,70$ and $90 \mathrm{mV} \mathrm{s}^{-1}$.

S5 - The study of the stability of the electrodes modified with polymers (Kp20 and Kpy20) was carried out in the same way as the electrodes of GR, KPO and NTCPM. Cyclic voltammograms and specific graphs of the correlation between Ipa and Epc vs the number of cycles, are illustrated.
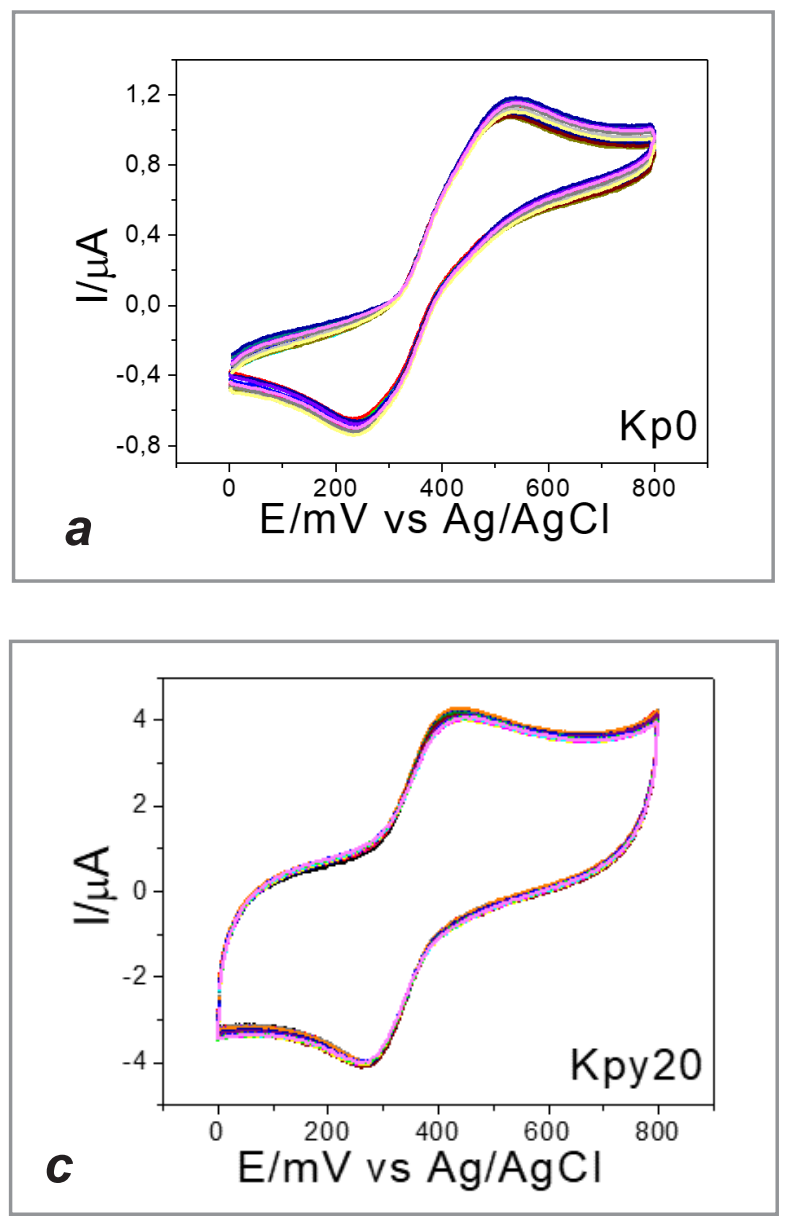

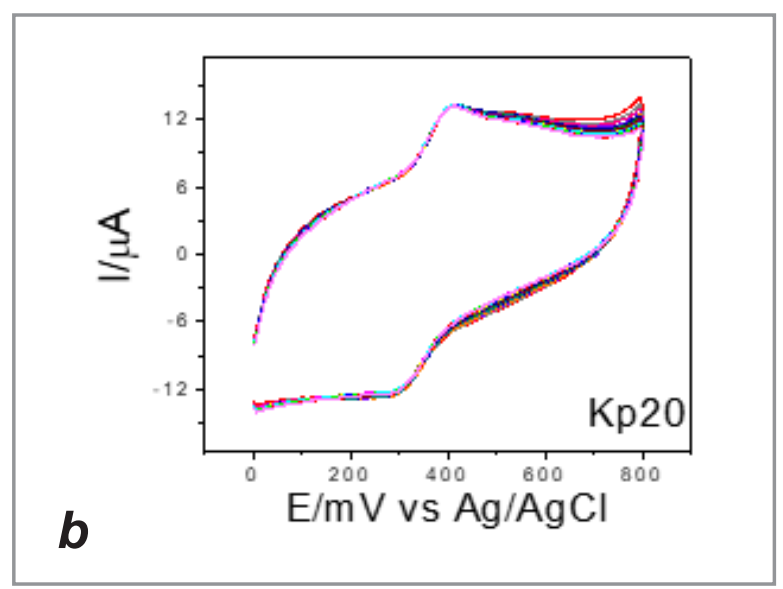

Figure S5. Cyclic voltammograms for the KPOPE (a), KPPE (b), KPyPE (c) in $50 \mu \mathrm{mol} \mathrm{L-1}$ of DA. Supporting electrolyte: $\mathrm{NaCl} 0.5 \mathrm{~mol} \mathrm{~L}^{-1}, \mathrm{pH} 4.0$ and $v=30 \mathrm{mV} \mathrm{s}^{-1}$. 
S6 - All electrodes (GR, Kp0, NTCPM, Kp20 and Kpy20) were studied individually to analyze the electrochemical behavior of each one before the simultaneous addition of dopamine and ascorbic acid. From the concentration of $1.0 \mathrm{mmol} \mathrm{L}^{-1}$, the KP20 electrode began to detect ascorbic acid, but at this concentration, the voltammogram still showed a small faradaic current from dopamine. The other electrodes from the concentration of $0.1 \mathrm{mmol} \mathrm{L}^{-1}$ have already detected ascorbic acid.
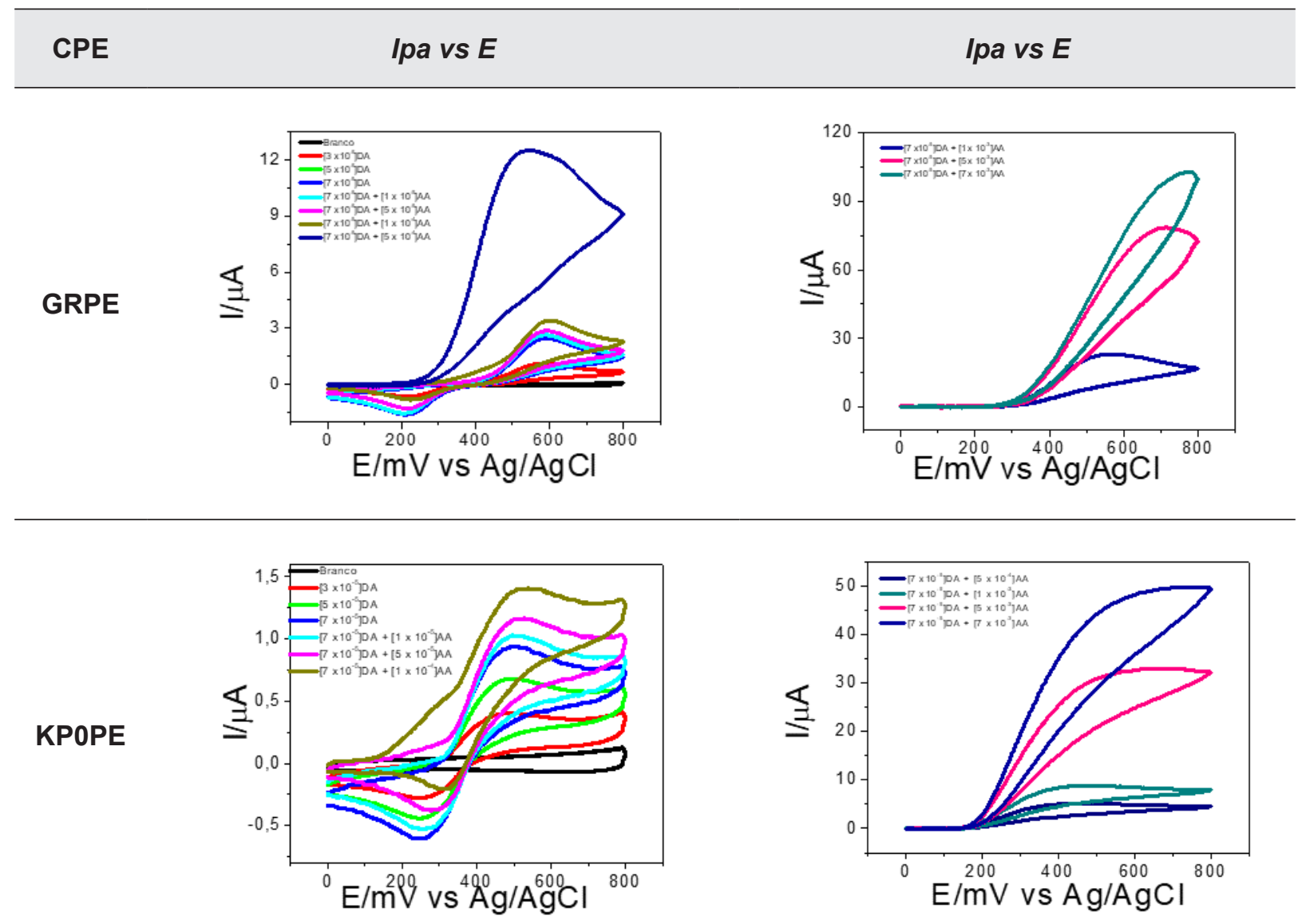

CNTPE
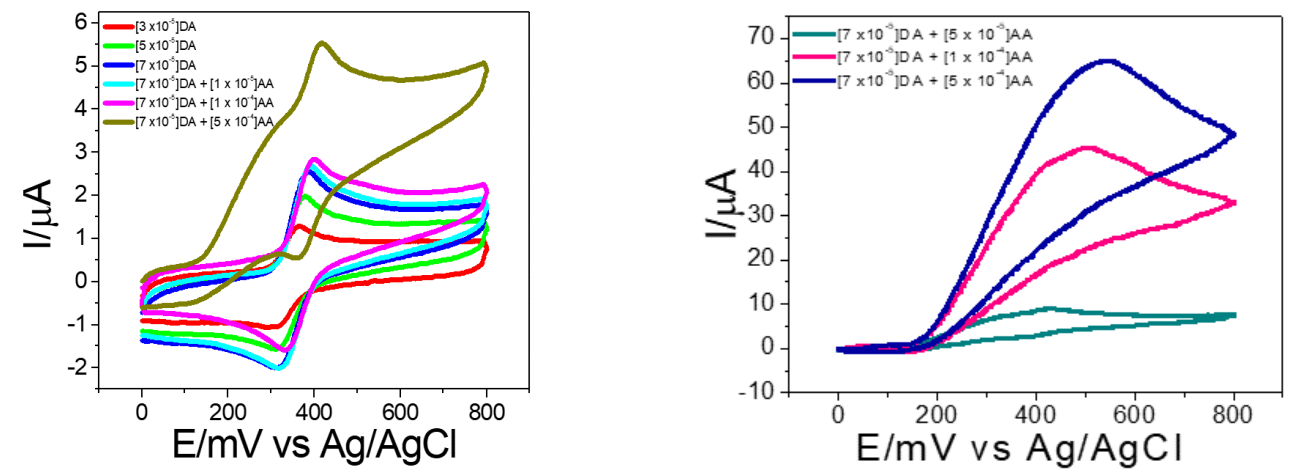

Figure S6. Cyclic voltammograms performed with KPPE, KPyPE, KPOPE, GRPE and CNTPE in DA $\left(3.0 \times 10^{-5}\right.$ to $\left.7.0 \times 10^{-5} \mathrm{~mol} \mathrm{~L}^{-1}\right)$. Once the dopamine concentration was fixed at $7.0 \times 10^{-5} \mathrm{~mol} \mathrm{~L}^{-1}$, the concentrations of ascorbic acid varied from $1.0 \times 10^{-5} \mathrm{~mol} \mathrm{~L}^{-1}$ to $7.0 \times 10^{3} \mathrm{~mol} \mathrm{~L}^{-1}$. 


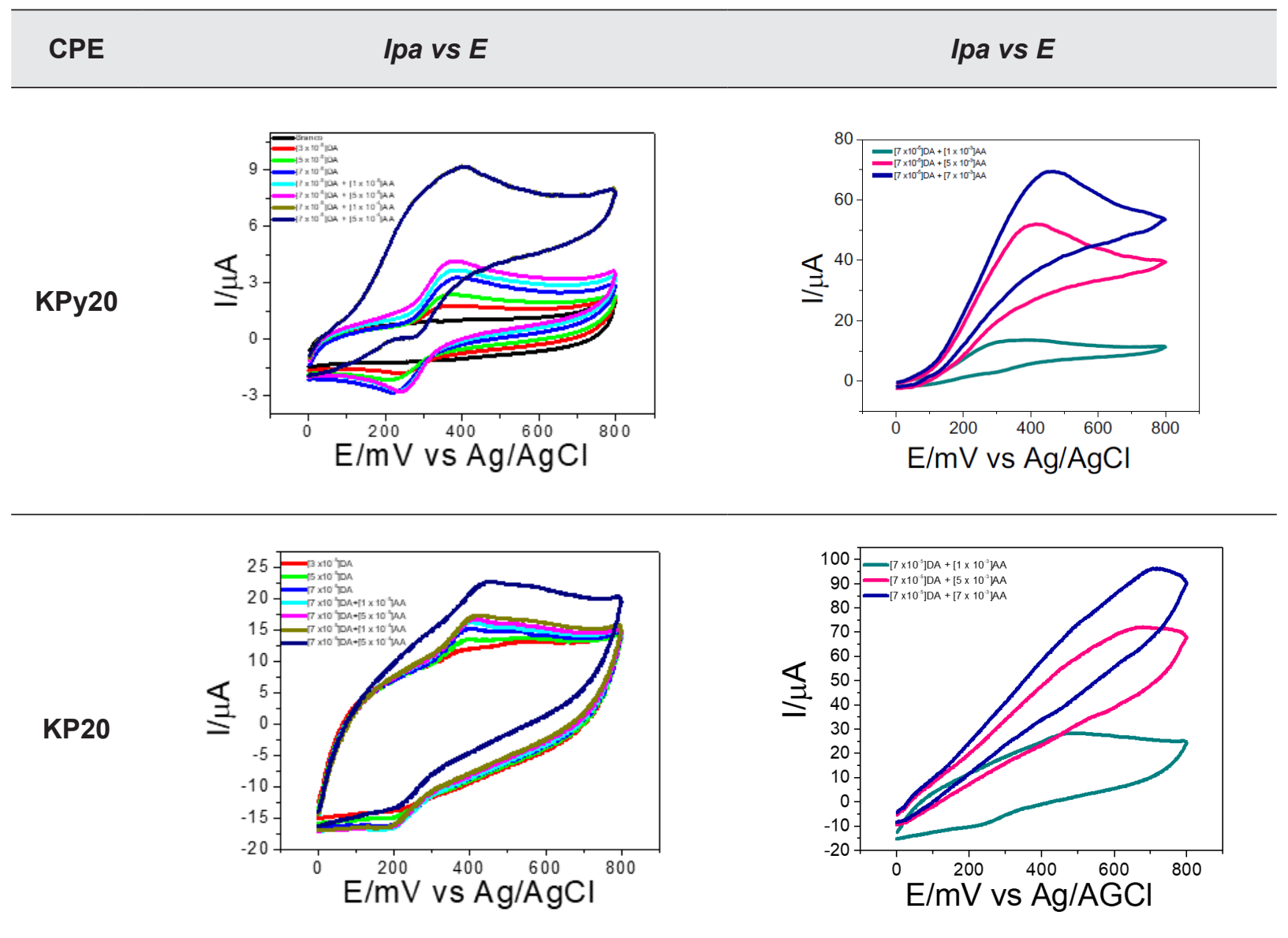

Figure $\mathbf{S 6}$ continuation. Cyclic voltammograms performed with KPPE, KPyPE, KPOPE, GRPE and CNTPE in DA $\left(3.0 \times 10^{-5}\right.$ to $\left.7.0 \times 10^{-5} \mathrm{~mol} \mathrm{~L}^{-1}\right)$. Once the dopamine concentration was fixed at $7.0 \times 10^{-5}$ $\mathrm{mol} \mathrm{L} \mathrm{L}^{-1}$, the concentrations of ascorbic acid varied from $1.0 \times 10^{-5} \mathrm{~mol} \mathrm{~L}^{-1}$ to $7.0 \times 10^{3} \mathrm{~mol} \mathrm{~L}^{-1}$. 